\title{
THE EFFECTS OF BASAL MELTING ON THE PRESENT FLOW OF THE ROSS ICE SHELF, ANTARCTICA
}

\author{
By D.R. MACAYEAL \\ (Department of the Geophysical Sciences, University of Chicago, Chicago, Illinois 60637, U.S.A.) \\ and R.H. THOMAS*
}

(Jet Propulsion Laboratory, California Institute of Technology, Pasadena, California 91109, U.S.A.)

\begin{abstract}
We use a hybrid finite-element/finitedifference model of ice-shelf flow and heat transfer to investigate the effects of basal melting on the present observed flow of the Ross Ice Shelf. Two hypothetical basal melting scenarios are compared: (i) zero melting everywhere and (ii) melting sufficient to balance any large-scale patterns of ice-shelf thickening that would otherwise occur. As a result of the temperature-dependent flow law (which we idealize as having a constant activation energy of $120 \mathrm{~kJ}$ $\mathrm{mol}^{-1}$, a scaling coefficient of $1.3 \mathrm{~N} \mathrm{~m}^{-2} \mathrm{~s}^{1 / 3}$, and an exponent of 3), simulated ice-shelf velocities for the second scenario are reduced by up to $20 \%$ below those of the first. Our results support the hypothesis that melting patterns presently maintain ice thickness in steady state and conform to patterns of oceanic circulation presently thought to ventilate the sub-ice cavity. Differences between the simulated and observed velocities are too large in the extreme south-eastern quarter of the ice shelf to permit verification of either basal melting scenario. These differences highlight the need to improve model boundary conditions at points where ice streams feed the ice shelf and where the ice shelf meets stagnant grounded ice.
\end{abstract}

RÉsumÉ. Influence de la fusion basale sur l'écoulement actuel $d u$ Ross Ice Shelf, Antartide. On utilise un modèle mixte aux éléments finis et différences finies de l'écoulement et du transfert de chaleur pour étudier l'influence de la fusion à la base sur l'écoulement actuellement observé du Ross Ice Shelf. Deux hypothèses sont envisagées: 1) fusion nulle partout et 2) fusion équilibrant tout épaissisement à grande échelle qui devrait se produire en son absence. Résultant d'une contre-réaction thermique (que nous supposons avoir une énergie d'activation de $120 \mathrm{~kJ} \mathrm{~mol}^{-1}$, un coefficient de $1,3 \mathrm{~N} \mathrm{~m}^{-2}$ $\mathrm{s}^{1 / 3}$ et un exposant ègal à 3 ) les vitesses d'expansion du shelf simulées dans le cas de la seconde hypothèse sont de $20 \%$ inférieures à celles qui résulteraient de la première. Nos résultats montrent que la répartition géographique de la fusion basale nécessaire au maintient des épaisseurs dans un

\section{INTRODUCTION}

The largest Antarctic ice shelves flow by forced horizontal extrusion through coastal embayments containing islands and sea-bed shoals. This extrusion is driven partly by seaward flow of outlet glaciers and ice streams entering the ice shelf and partly by the release of gravitational potential energy associated with local ice-shelf thinning (Weertman, 1957; Swithinbank and Zumberge, 1965; Budd, 1966). Basal melting can potentially modify this extrusion in

*Present address: Royal Aircraft Establishment, Farnborough GU14 6TD, Hampshire, England. état stationnaire sont réalistes et en accord avec la circulation océanique sous glaciaire supposée. Les différences entre vitesses calculées et vitesses observées sont trop importantes dans le quart Sud Est du shelf pour permettre de vérifier l'une des deux hypothèses de fusion basale. Ces différences montrent la nécessité de perfectionner les conditions aux limites dans les régions où les fleuves de glace alimentent le shelf et dans celles où le shelf est en contact avec de la glace stagnante reposant sur le lit.

Zusammenfassung. Die Wirkung des Schmelzens an der Unterseite auf den derzeitigen Fluss des Ross Ice Shelf, Antarktika. Zur Untersuchung der Wirkung des Schmelzens an der Unterseite auf den derzeit beobachteten Fluss des Ross Ice Shelf wird ein hybrides Modell mit finiten Elementen bzw. finiten Differenzen für den Schelfeisfluss und die Wărmeübertragung herangezogen. Zwei hypothetische Zustånde des Schmelzens an der Unterseite werden verglichen: (1) Fehlen jeglichen Schmelzens; (2) Schmelzen in einem Ausmass, das der Dickenzunahme des Schelfeises in weiten Bereichen, die sonst eintreten würde, die Waage hält. Infolge des temperaturabhăngigen Fliessgesetzes (das wir insofern idealisieren, als wir eine konstante Aktivationsenergie von $120 \mathrm{~kJ} \mathrm{~mol}^{-1}$, einen Eichkoeffizient von $1,3 \mathrm{~N} \mathrm{~m}^{-2} \mathrm{~s}^{1 / 3}$ und einen Exponenten 3 annehmen) liegen die simulierten Schelfeisgeschwindigkeiten beim zweiten Zustand bis zu 20\% niedriger als beim ersten. Unsere Ergebnisse stützen die Annahme, dass die Verteilung des Abschmelzens derzeit die Eisdicke stationăr und in Übereinstimmung mit der Struktur der ozeanischen Zirkulation, die den Hohlraum unter dem Eis durchmischen dürfte, hălt. Die Unterschiede zwischen den simulierten und den beobachteten Geschwindigkeiten sind im ăussersten Südostviertel des Schelfeises zu gross, als dass sie eine Bestătigung für einen der beiden Schmelzzustände am Untergrund zuliessen. Diese Unterschiede weisen erneut auf den Bedarf an verbesserten Modell-Randbedingungen an Stellen, wo Eisstrőme das Schelfeis ernăhren und wo das Schelfeis mit stagnierendem, aufsitzendem Eis zusammentrifft, hin.

three ways: (i) it can reduce the force that drives horizontal spreading; (ii) it can modify the total coastal friction resisting seaward flow; and (iii) it can cool the depth-averaged temperature and thus reduce the rate of ice-shelf deformation in response to a given stress.

Sanderson (1979) examined the first and second of these effects by calculating equilibrium ice-shelf thickness and velocity distributions for various idealized coastal embayments. His analysis demonstrated that spatially uniform melting increases the down-stream thickness slope and reduces the velocity and horizontal strain-rates. These changes result primarily from direct removal of ice-shelf mass which thereby reduces the gravitational driving stress. For embayments with straight but divergent coasts, uniform melting was found to shorten the length between the 
grounding line and the separation point where transverse spreading is no longer able to maintain contact between the ice shelf and coasts. By shortening this length, basal melting can potentially reduce the net coastal friction, or "back stress", that maintains the dynamic stability of marine ice sheets (Thomas, 1979). Modification of this back stress may thus constitute a significant coupling between continental ice and the ocean.

Our investigation seeks to extend Sanderson's (1979) results by evaluating the potential impact of basal melting on the present observed flow of the Ross Ice Shelf. Since we address the present ice-shelf thickness and size, our evaluation focuses on the effect of melting on the present depth-averaged temperature. Basal melting erodes the warmest part of the ice column nearest the ocean/ice interface and thereby lowers the depth-averaged temperature (Crary, 1961; MacAyeal, unpublished [b]). Strain-rates in ice under a fixed stress are strongly diminished by decreasing temperature (Hooke, 1981) thus an ice shelf subject to basal melting will tend to stiffen. Although heat conduction within the ice column tends to counterbalance the effects of melting on the depth-averaged temperature, the thermal conductivity of ice is so low that conductive re-adjustment to a step-like basal melting change may take several hundred years (MacAyeal, unpublished [b]). During readjustment a typical ice column of a major Antarctic ice shelf can travel several hundred kilometers. It is therefore reasonable to expect reduced creep-rate "shadows" extending down-stream of localized sites of basal ablation. As an illustration of this concept, we present in Appendix A simple examples of ice-shelf response to basal melting that were generated using Sanderson's (1979) methods.

To identify the thermal signature of basal melting in the Ross Ice Shelf flow, two methods are available: (i) conduct a comprehensive survey of temperature-depth profiles throughout the ice shelf with a horizontal resolution selected to detect the dominant spatial variability of basal melting zones, or (ii) use the observed relationship between thickness and deformation as a diagnostic indicator of thermal conditions. The first method is difficult because it requires ice drilling or electrical resistivity profiling (Shabtaie and Bentley, 1979). Local surveys are possible (Clough and Hansen, 1979; Shabtaie and Bentley, 1979) but they are most useful for verification of precisely defined regions of basal melting. The second method is attempted in this study using observations made during the Ross Ice Shelf Glaciological and Geophysical Survey (RIGGS) and other field programs (Zumberge, 1964; Bentley and others, 1979; Thomas and others, 1984).

In order to evaluate the relationship between observed thickness and deformation of a complex ice shelf potentially subject to spatially non-uniform melting, we must: (i) solve the momentum-balance and constitutive equations for the flow associated with non-uniform ice thickness and irregular boundaries, and (ii) solve the heat-transfer equation taking into account horizontal advection effects. In a previous paper (Thomas and MacAyeal, 1982), we reported results obtained from analytic formulae for ice-shelf spreading rates and a simple one-dimensional numerical treatment of heat transfer. The formulae are adequate to the extent that certain simplifying assumptions are satisfied by the complex thickness patterns and boundary conditions of the Ross Ice Shelf (see Thomas and MacAyeal, 1982). The onedimensional heat-transfer analysis, however, is inadequate because it does not treat horizontal ice-column advection that may permit reduced creep-rate "shadows" to extend down-stream of restricted zones of basal melting.

In this study, we use the finite-element method to solve the momentum-balance, constitutive, and heat-transfer equations. This method provides a general solution for depth-independent flow in an ice shelf of any shape and provides a fully three-dimensional solution of the steadystate heat-transfer equation with horizontal advection terms. Here, we simulate ice-shelf flow and temperature distribution for two alternative basal melting scenarios and then compare these simulations with observations.

Despite the powerful and computationally expensive methods we use, we have not yet obtained acceptable agreement between simulated and observed flow patterns. This disagreement stems largely from inadequate boundary con-

ditions required by numerical models such as ours. Nevertheless, we believe that our results provide several specific constraints on the nature of prevailing basal melting patterns, such as: (i) whether the pattern of basal melting required to maintain in "steady state" the observed icethickness distribution is compatible with observed creep rates; (ii) whether basal melting patterns implied by recent oceanographic field work and theory are compatible with observed creep rates; and (iii) whether basal sea-ice layers derived from the above patterns are compatible with ice cores, radio echo-sounding, and electrical resistivity observations (Neal, 1979; Shabtaie and Bentley, 1979; Zotikov and others, 1980; Jezek, 1984).

\section{GOVERNING EQUATIONS}

The momentum and heat-balance equations used in this study are written:

$$
\nabla \cdot \sigma+\rho g=0
$$

and

$$
\frac{\partial \theta}{\partial t}=-u \cdot \nabla_{H} \theta+k \frac{\partial^{2} \theta}{\partial z}-w \frac{\partial \theta}{\partial z}
$$

where, $x, y, z, t$ are horizontal ( $x$ and $y$ ) and vertical $(z$, positive upwards) coordinates (see Fig. 17) and time (t), and

$\nabla$

$\theta(x, y, z, t) \quad$ ice temperature $\left({ }^{\circ} \mathbf{K}\right)$,

$w$

$\nabla_{\mathbf{H}}$

* thermal diffusivity of ice (assumed constant at $1.4 \times 10^{-6} \mathrm{~m}^{2} / \mathrm{s}$ (Weller and Schwerdtfeger, 1971).

Equation (1) describes the balance of forces within the ice (assumed to be crevasse-free), and can be solved for the ice velocity provided: (i) a constitutive relation is prescribed, and (ii) appropriate boundary conditions are specified. The constitutive relation used here is the "ice-flow law" adapted from that used by Hooke and others (1979) in a similar modeling study, and is written:

$$
\sigma^{\prime}=2 v \dot{\epsilon}
$$

where, $\sigma^{\prime}$ is the deviatoric stress (Paterson, 1969)

$$
v=\frac{B}{2\left|\dot{\epsilon}^{2}\right|^{1 / 3}}
$$

and

$$
B=B_{0} \rho(z) / \rho_{\mathrm{i}} \exp \{Q / 3 R \theta(z)\} .
$$

For simplicity, we assume that firn densification and elastic strains are uncoupled from the large-scale creep deformation. This assumption provides the incompressibility constraint

$$
\nabla_{\mathrm{H}} \cdot u+\frac{\partial w}{\partial z}=0 .
$$


The symbols used above are

$\checkmark \quad$ effective viscosity,

E strain-rate tensor,

$\left|\dot{\epsilon}^{2}\right| \quad\left(\frac{1}{2} \dot{\epsilon}_{i j} \dot{\epsilon}_{i j}\right)$ where $\dot{\epsilon}_{i j}$ is the $i j^{\text {th }}$ component

of $\epsilon$ (indices $i$ and $j$ denote components along $x, y$, and $z$ ),

$\dot{B}$

flow-law parameter (distinct from basal accumulation rate $B$,

$B_{0}$

$1.3 \mathrm{~N} \mathrm{~m}^{-2} \mathrm{~s}^{1 / 3}$ (see Thomas and MacAyeal (1982) for justification),

creep activation energy $(120.0 \mathrm{~kJ} / \mathrm{mol})$ (see Thomas and MacAyeal (1982) for justification),

$R$

universal gas constant $\left(8.3143 \mathrm{~J} / \mathrm{mol}{ }^{\circ} \mathrm{K}\right)$

(Weast, 1968).

This constitutive relation is derived from laboratory measurements of the deformation of isotropic ice samples under applied loads (Glen, 1955; Hooke, 1981) and is consistent with field observations of unconfined ice-shelf flow (Thomas, 1973). The laboratory-derived values of $B_{0}$ and $Q$ used here represent soft ice conditions normally applicable at temperatures warmer than $260 \mathrm{~K}$. Despite laboratory work indicating that ice colder than $260 \mathrm{~K}$ is stiffer with $B_{0}$ and $Q$ having values of $625 \mathrm{~N} \mathrm{~m}^{-2} \mathrm{~s}^{1 / 3}$ and $80 \mathrm{~kJ}$ $\mathrm{mol}^{-1}$, respectively (Barnes and others, 1971), values representing softer, warmer ice are applied uniformly in this study. In view of the inadequate treatment of ice-shelf boundary conditions described below, a sensitivity analysis of $B_{0}$ and $Q$ would have been unproductive, so was not attempted. No attempt is made either to parameterize faults, crevasses, anomalous strain heating, and anisotropic fabric.

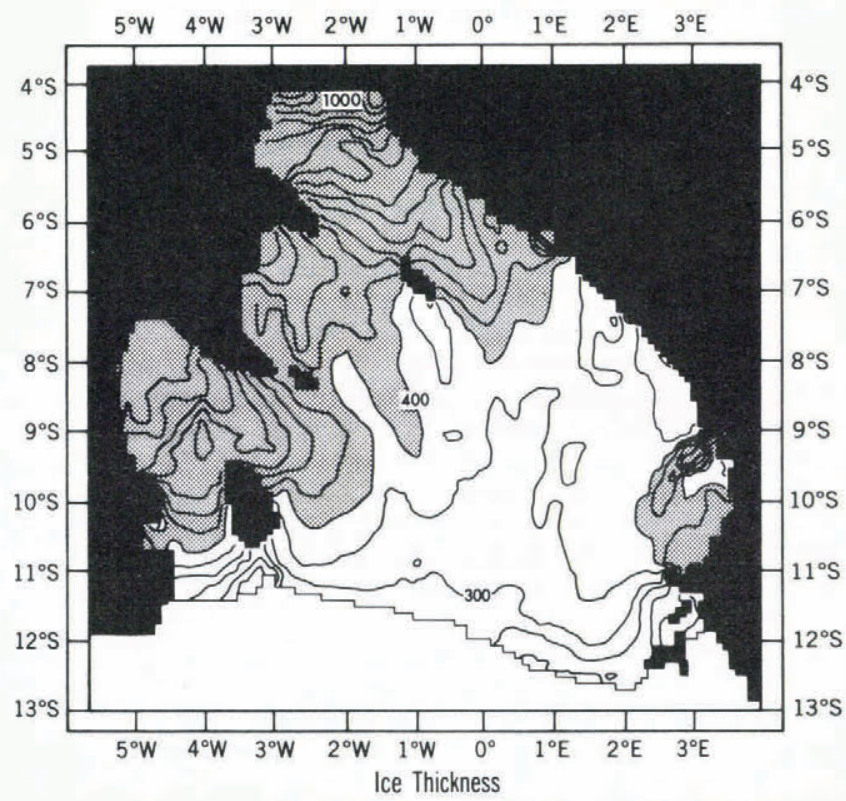

Fig. 1. Observed thickness of the Ross Ice Shelf (Bentley and others, 1979). Coordinates indicated along the edges of this map are called "grid-coordinates" and are adopted here to be consistent with published maps of field data (e.g. fig. 1 of Bentley and others (1979)). In the grid-coordinate system, the North Pole is placed at the intersection of the Equator and the prime meridian. All directions, latitudes, and longitudes explicitly referred to in the text are taken with respect to the geographical coordinate system. All map projections presented here are polar stereographic and are referenced to the geographic South Pole.
The factor $\rho(z) / \rho_{\mathrm{i}}$ in Equation (5) represents our ad hoc representation of firn-layer strength. A more accurate treatment of firn-layer strength, perhaps using a Coulomb rheology (Jaeger and Cook, 1976), could potentially improve the model in regions of low ice thickness where firn comprises a major part of the ice column.

The horizontal components of long-term and large-scale ice-shelf flow under consideration here are naturally independent of depth because thickness gradients, basal shear stresses, and variation of viscosity with depth are insufficient to induce significant vertical shear (Weertman, 1957; Sanderson and Doake, 1979). This property allows us to simplify our model by integrating Equation (1) over depth to eliminate one spatial dimension from the numerical domain. Equation (2) must be solved within a threedimensional domain, however, because vertical and horizontal processes operate simultaneously. The numerical techniques used in this study are described in Appendix B.

Solution of Equations (1) through (6) provides a "snapshot" of the instantaneous flow and temperature. Time dependence of the flow is governed by the mass-balance equation (not shown), determining $H(t)$ and the heat equation determining $\theta(t)$. In this study, the ice-thickness distribution is held fixed at its present observed state, shown in Figure 1. The time-derivative term in the heat equation is retained artificially, however, and is used as a computational technique for generating a temperature distribution in steady-state balance with a prescribed basal melting scenario and self-consistent with the temperaturedependent flow velocities. This technique of coupling iceshelf dynamics and thermodynamics is referred to as "asynchronous coupling" and is discussed in detail under a separate heading.

\section{BOUNDARY CONDITIONS}

Velocity or stress must be prescribed on all surfaces bounding the ice shelf as boundary conditions for Equation (1). On the ice front and ice-shelf base, we specify hydrostatic sea-water pressure (assuming a constant sea-water density $\rho_{w}$ of $1028.0 \mathrm{~kg} / \mathrm{m}^{3}$ appropriate to Ross Sea conditions (Jacobs and others, 1979)) and zero shear stress. On the upper ice-shelf surface, we specify zero total stress (we disregard atmospheric effects). Velocity or stress conditions at the grounded-ice/floating-ice and the floating-ice/mountain-wall contacts are generally unknown because of insufficient field observation. Here we specify all such boundary conditions in terms of velocity. Along stagnant ice margins (edges of ice rises, edges of grounded ice where no outlet glacier or ice stream exists, mountain

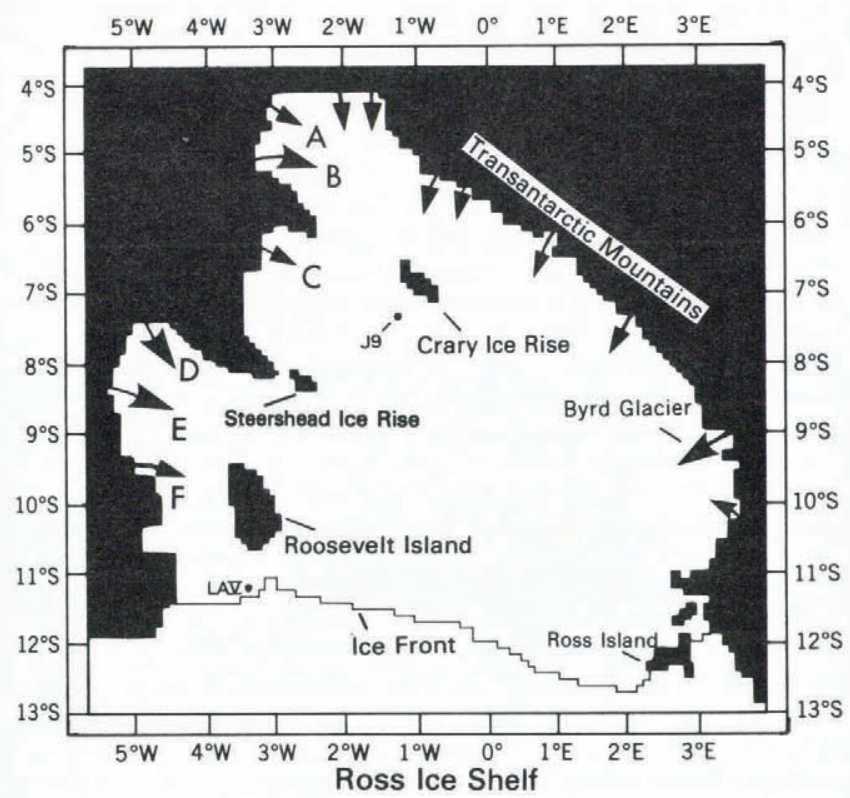

Fig. 2. Names of locations and features on the Ross Ice Shelf. Ice-stream and glacier influx are shown schematically. 
walls), we arbitrarily set the velocity to zero. For glaciers flowing through the Transantarctic Mountains and for West Antarctic ice streams (see Figure 2 and Hughes (1975), Giovinetto and others (1966), and Swithinbank (1963) for descriptions and locations of these geographic features), we specified velocities estimated from neighboring ice-shelf measurements. These velocities and associated ice-volume fluxes are compared with field observations in Table I.

Differences between the observed velocities and the specified input velocities result from finite grid resolution and our attempt to correctly represent within limits of error the observed ice-volume flux (defined as the integral of velocity over the cross-sectional area of the outlet glacier or ice stream). The finite limit of spatial resolution $(10 \mathrm{~km})$ inherent in our numerical grid necessitated some adjustment of the input velocity from that observed (assumed constant over the width of the glacier or ice stream) to attain the desired flux. In addition, we favored an increased value of the ice-volume flux (within the limits of observed error, if relevant) to account for other glaciers not explicitly modeled and for general ice-sheet drainage between ice streams.

For ice streams A through F, few field data are available to constrain our input velocities and fluxes. We thus extrapolated the desired input velocities from neighboring points on the ice shelf where velocities were observed during RIGGS (see Thomas and others (1984) for description of observations). We remark that agreement between the observed and simulated flow along the eastern grounding line could have been improved had we used higher ice-stream input velocities and fluxes. Such high velocities would have exceeded the upper boundary we believe to constrain plausible ice-stream velocities. In fact, our input velocities are well above those inferred from icethickness patterns by Robin (1975). We therefore suspect that specified ice-stream input velocities must presently be unrealistically high so as to overcome excessive restraining forces produced by the model elsewhere in the ice shelf.

Equation (2) describes the evolution of the temperature in response to both vertical and horizontal advection, and to vertical conduction. Horizontal conduction and viscous heat generation are disregarded in our model. The vertical variation of conductivity, heat capacity, and velocity in the firn layer are also disregarded because of insufficient vertica resolution which is $1 / 9$ the local ice thickness. Boundary conditions required for Equation (2) are: (i) the surface temperature $\left(\theta_{\mathrm{s}}\right)$ determined from observed $10 \mathrm{~m}$ bore-hole temperatures (Thomas and others, 1984), (ii) the basal freezing temperature $\left(\theta_{b}\right)$ determined from the pressuredependent freezing-point relation at an assumed salinity of $34.75 \%$ (Fujino and others, 1974), and (iii) the temperature-depth profile at all ice-stream inflow boundaries. For want of observations, condition (iii) is computed from a version of Equation (2) in which the horizontal advection terms have been truncated. This results in a version of condition (iii) that idealizes the ice streams and outlet glaciers as being charcteristically similar to ice shelves. To obtain $w(z)$, we apply the incompressibility constraint and adopt a stretched vertical coordinate system to account for snow accumulation denoted by $\dot{A}$ (m of ice/s) and basal accumulation denoted by $\dot{B}$ (m of ice/s) (see Appendix B). Values of $\dot{A}$ derived from RIGGS observations (see Thomas and others, 1984) were used as model input and are shown in Figure 3. For some of the experiments, $\dot{B}$ was specified; in others, $\dot{B}$ was constrained to balance the effects of snow

TABLE I. ICE-STREAM AND GLACIER INPUT PARAMETERS

\begin{tabular}{|c|c|c|c|c|c|c|c|c|}
\hline Ice streams & $\begin{array}{l}\text { Input } \\
\text { velocity } \\
\mathrm{m} / \mathrm{a}\end{array}$ & $\begin{array}{l}\text { Input } \\
\text { width } \\
\text { km }\end{array}$ & $\begin{array}{c}\text { Input } \\
\text { thickness } \\
\mathrm{m}\end{array}$ & $\begin{array}{l}\text { Input } \\
\text { ice flux } \\
\mathrm{km}^{3} / \mathrm{a}\end{array}$ & $\begin{array}{c}\text { Observed } \\
\text { velocity } \\
\mathrm{m} / \mathrm{a}\end{array}$ & $\begin{array}{l}\text { Observed } \\
\quad \text { flux } \\
\mathrm{km}^{3} / \mathrm{a}\end{array}$ & $\begin{array}{c}\text { Inde pendently } \\
\text { Velocity } \\
\mathrm{m} / \mathrm{a}\end{array}$ & $\begin{array}{c}\text { estimated }^{\ddagger} \\
\text { Flux } \\
\mathrm{km}^{3} / \mathrm{a}\end{array}$ \\
\hline A & 225 & 28 & 1000 & 6.3 & - & - & 100 & \\
\hline B & 750 & 40 & 850 & 25.5 & - & - & 450 & \\
\hline C & 150 & 40 & 650 & 3.9 & - & - & 350 & 16.5 \\
\hline D & 550 & 22 & 800 & 9.7 & - & - & 550 & 31.5 \\
\hline E & 650 & 40 & 800 & 20.8 & - & - & 180 & \\
\hline F & 200 & 10 & 650 & 1.3 & - & - & & \\
\hline Outlet glaciers & & & & & & & & \\
\hline Mulock Glacier & 285 & 22 & 450 & 2.8 & 290 & $2.8 \pm 0.5$ & & \\
\hline Byrd Glacier & 600 & 36 & 650 & 14.0 & $740 \pm 10^{\S}$ & $16.3 \pm 1.63$ & & \\
\hline Nimrod Glacier & 250 & 22 & 500 & 2.7 & 150 & $2.2 \pm 0.7$ & & \\
\hline Beardmore Glacier & 470 & 28 & 650 & 8.5 & 330 & $5.8 \pm 1.7$ & & \\
\hline Shackleton Glacier & 170 & 10 & 550 & 0.9 & - & - & & \\
\hline Liv Glacier & 230 & 10 & 700 & 1.6 & $70 \pm 10$ & $0.5 \pm 0.1$ & & \\
\hline Amundsen Glacier & 170 & 10 & 1100 & 1.9 & $150 \pm 10$ & $3.3 \pm 1.7$ & & \\
\hline Scott Glacier & 170 & 10 & 1100 & 1.9 & $180 \pm 10$ & $2.0 \pm 0.4$ & & \\
\hline
\end{tabular}

* Model input velocity and thickness were assumed constant across the widths of the ice streams or glaciers.

† Swithinbank, 1963; Giovinetto and others, 1966.

‡ Hughes, 1975.

$\S$ Brecher, 1982. 


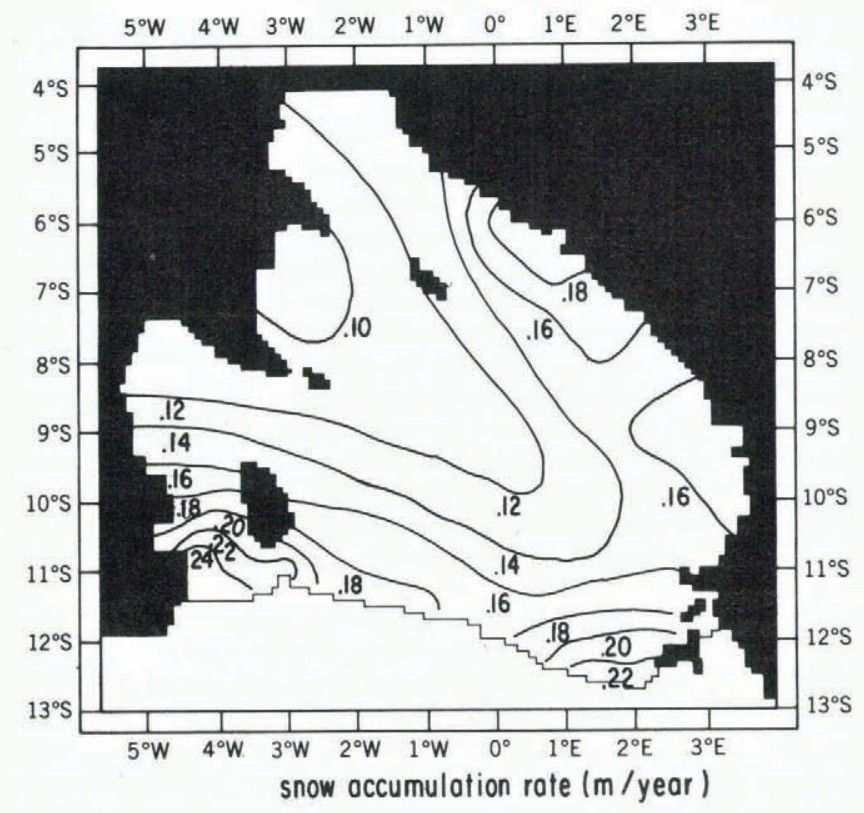

Fig. 3. Observed snow-accumulation rate expressed in meters of ice equivalent per year (Thomas and others, 1984).

accumulation and ice-shelf spreading. For computational purposes, we specify an analytic approximation to a steadystate temperature profile (Crary, 1961) as an initial condition. This condition is "forgotten", however, because Equation (2) is integrated through time while artificially holding $H(t)$ fixed until a "steady-state" temperature distribution is obtained.

\section{ASYNCHRONOUS COUPLING}

The goal of our investigation is to determine the thermodynamic signal of basal melting in the present deformation rate of the Ross Ice Shelf. This presents a serious difficulty because the temperature distribution depends on past ice-shelf history; whereas, the deformation rate results from present instantaneous distributions of ice thickness and temperature. To calculate present ice-shelf temperature correctly, it is necessary to prescribe ice thickness and flow over the prior history of the ice shelf. This history is not sufficiently known to make such a calculation possible. We compromise by calculating instead the prior thermal evolution while artificially holding ice thickness fixed at its present value. We call this procedure asynchronous time marching (see Manabe and Bryan, 1969).

In brief, our procedure is: (i) step Equation (2) forward in time until $\theta$ converges to a stationary solution while holding $H, \dot{A}, \theta_{\mathrm{b}}$, and $\theta_{\mathrm{s}}$ fixed at the present observed values, and holding $\dot{B}$ fixed at a prescribed value, and (ii) periodically update $u$ to account for horizontal advection-rate changes caused by feedback between temperature and the flow-law parameter $B$. During this artificial time evolution, initial conditions are "forgotten"; and the temperature distribution and temperature-dependent ice velocities approach a self-consistent steady state. The temperature and effective viscosity are stepped forward through 3000 years of "evolution" with velocity updated every 50 years to account for the changing flow-law parameter. The prescribed basal melting rate is updated every 500 years, if it was specified using information derived from the simulated flow fields (see next section). We stress that this asynchronous time-marching scheme is artificial and is useful only to provide a self-consistent estimate of the present temperature and temperature-dependent advection patterns. This scheme represents an outgrowth of previous techniques used successfully to simulate observed bore-hole temperatures (MacAyeal and Thomas, 1979; Young, 1981; MacAyeal, unpublished [b]).

In practice, we found that the above procedure would converge provided imposed basal freezing rates were not tied to simulated horizontal divergence rates in zones of high divergence down-stream of ice rises. In such cases, we found that positive feedback between warm temperatures associated with freezing and high flow divergence forced the temperature and flow to diverge from a reasonable solution. We did not continue these divergent simulations to see what alternative steady-state solutions would exist.

\section{ZERO BASAL ABLATION vs MAINTENANCE OF STEADY STATE}

We performed three simulations to evaluate the differences in ice-shelf flow between an imposed absence of basal melting and an imposed basal melting/freezing rate consistent with maintenance of steady-state ice thickness. In Run 1 we set $\dot{B}=0$. The velocity vectors and magnitude describing this simulation are shown in Figures 4 and 5 . In Run 2, we unsuccessfully tried to impose a basal melting

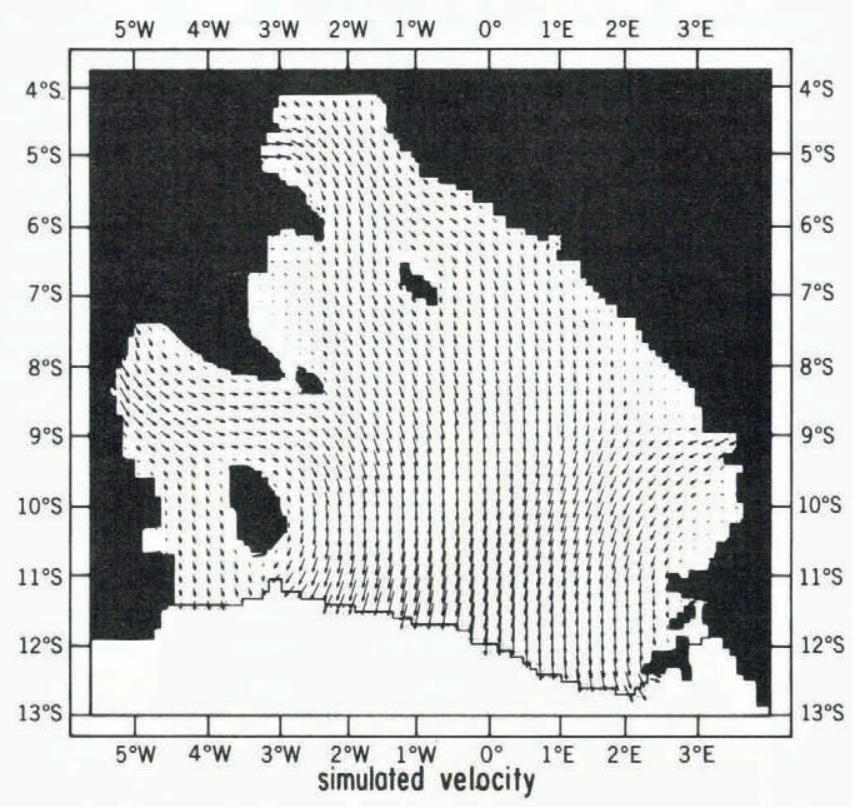

Fig. 4. The simulated velocity vectors of Run 1 are plotted at every other grid point. These velocities are assumed independent of depth.

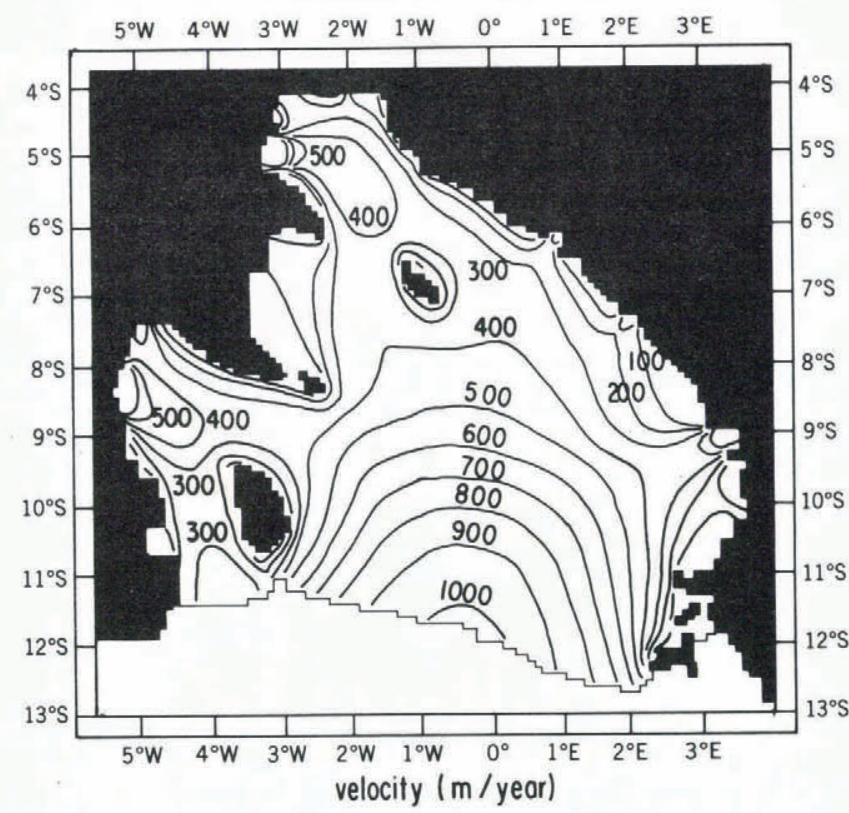

Fig. 5. The simulated isotachs of Run 1. These can be compared with the observed isotachs displayed in figure 1 of Thomas and MacAyeal (1982). 
rate consistent with a steady-state ice thickness in its present configuration:

$$
\dot{B}=-\dot{A}+\overline{\nabla_{\mathrm{H}} \cdot(u H)^{x}} x, y
$$

where $A$ is the observed snow-accumulation rate expressed in meters of ice per year shown in Figure 3 (Thomas and others, 1984). $H$ is the observed ice thickness (Bentley and others, 1979) (Fig. 1), and $\boldsymbol{u}$ is the horizontal velocity calculated by the numerical model. A spatial smoothing operator, denoted by $-x, y$, was applied to the divergence term to eliminate irregular grid-point-to-grid-point "spikes" having the minimum spatial scale resolvable by our numerical model $(10 \mathrm{~km})$. This smoothing was accomplished by setting the value of $\nabla_{\mathrm{H}} \cdot(u H)$ at each interior grid point of our model domain equal to the average of its value at the eight closest interior grid-point neighbors (see Appendix B). Both $\dot{B}$ and $u$ were updated periodically during the asynchronous time-marching procedure to insure compatability between $\overline{\nabla_{H} \cdot(u H)} x, y$ and the changing effective viscosity.

Convergence was not achieved for Run 2 because of an unstable positive feedback between basal freezing and strong ice divergence $\overline{\left(\nabla_{\mathbf{H}} \cdot(u H)\right)} x, y$ in the lee of Crary and Steershead Ice Rises. To illustrate this point, Figure 6 presents a map of the simulated thickening tendency

$\left.\overline{\left(-\dot{A}+\nabla_{\mathrm{H}} \cdot(u H)\right.}\right) x, y$ associated with Run 1 (zero $\dot{B}$ ). If the rule expressed by Equation (8) for specifying $\dot{B}$ is applied to the thickening tendencies shown in Figure 6 , then substantial basal freezing is required in the central sections of the ice shelf and particularly down-stream of Crary and Steershead Ice Rises. Warming of the depth-averaged temperature associated with this freezing would tend to increase the ice-divergence rates, which in turn would require greater freezing rates and even warmer temperatures. We terminated our simulation of Run 2 once the ice-front velocities exceeded about $2000 \mathrm{~m} /$ year, which is about twice their observed value.

Convergence failure in Run 2 resulted primarily from zones of high ice divergence occurring down-stream of the two major ice rises. These zones are generic parts of the typical ice-flow "signature" associated with ice rises in our numerical model. We postulated in a previous study that up-stream convergence combined with down-stream divergence comprises this "signature" and implies up-stream ice-rise migration along sea-bed ridges extending parallel to the flow lines (MacAyeal and Thomas, 1983). We further

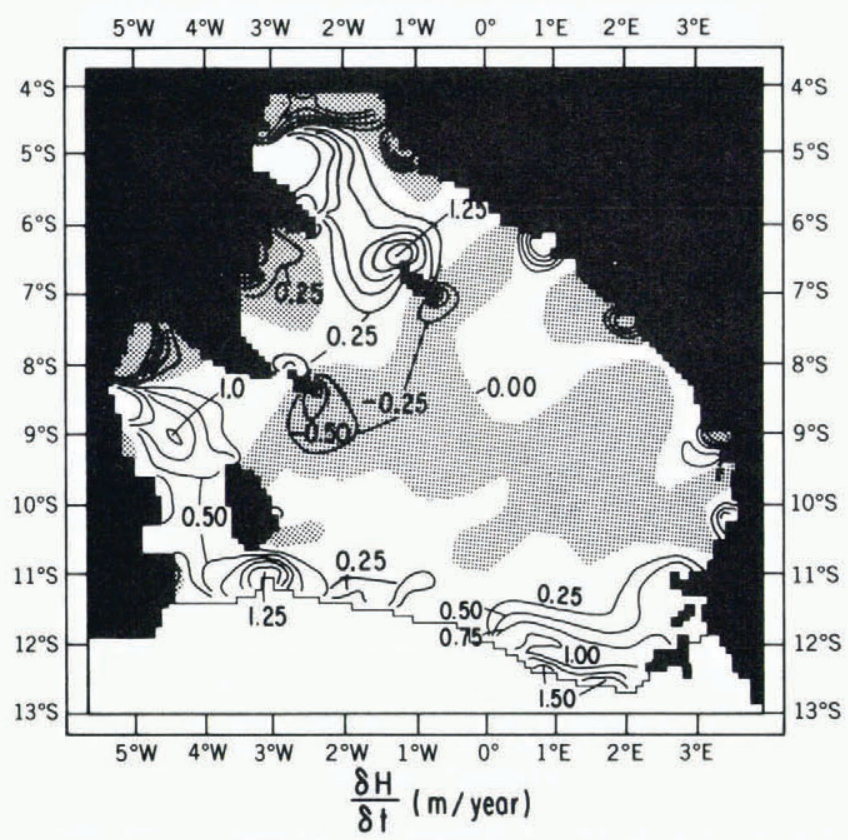

Fig. 6. The ice-thickness growth rate $(\mathrm{\partial H} / \mathrm{\partial t})$ of Run 1 is contoured at intervals of $0.25 \mathrm{~m} /$ year. The zero-growth contour is eliminated but regions of ice thinning are indicated by shading. speculated that such migration could be organized into a quasi-periodic "wave train" of several ice rises situated along a sea-bed ridge, such as those ridges common to the Ross Sea (Greischar and Bentley, 1980; MacAyeal and Thomas, 1982). Recent analysis of field data by Jezek (1984) lends some support to our speculation by indicating that the down-stream (north-western) edge of Crary Ice Rise has migrated up-stream over the last several hundred years.

Conditions immediately down-stream from an ice rise may be incompatible with steady state for two reasons: first, because of ice-rise migration; and secondly, because of ice-shelf fracture and cavitation. Consequently, we chose to abandon Run 2 and to run a third simulation in which imposed basal melting was sufficient to maintain steady state in all regions except for the zones of high divergence down-stream of ice rises. In these zones, basal freezing was limited to the value given by a balance between latent-heat release and upward heat flux through the ice shelf. We additionally imposed a high basal melting rate $(5.0 \mathrm{~m} /$ year $)$ within a $10 \mathrm{~km}$ strip along the ice front. This additional feature was imposed to test the proposition that diminished observed strain-rates along the ice front imply high local basal melting (Thomas and MacAyeal, 1982). The values of $\dot{B}$ imposed in Run 3 are

$$
-\dot{A}+{\overline{\nabla_{\mathrm{H}}(\boldsymbol{u} H)}}^{x, y} \text { where }-\dot{A}+{\overline{\nabla_{\mathrm{H}}(\boldsymbol{u} H)}}^{x, y} \leqslant-\left.\frac{k}{\rho_{\mathrm{i}} L} \frac{\partial \theta}{\partial z}\right|_{z=\text { base }}
$$

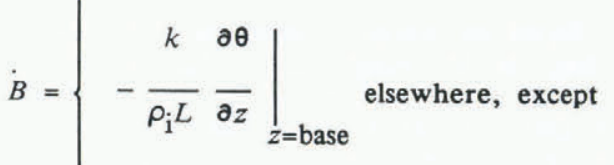

- $5.0 \mathrm{~m} /$ year (melting) within $10 \mathrm{~km}$ of ice front

where $k\left(2.24 \mathrm{~W} \mathrm{~m}^{-1} \mathrm{~K}^{-1}\right)$ is the conductivity of ice at the freezing temperature (Weller and Schwerdtfeger, 1971) and $L\left(3.35 \times 10^{5} \mathrm{~J} / \mathrm{kg}^{-1}\right)$ is the latent heat of fusion (Weast, 1968). Convergence of the asynchronous time-marching scheme was successful. Figure 7 shows the values of $B$ that resulted from Equation (9) once the flow and temperature distributions converged. Figure 8 shows the velocity-magnitude difference between Runs 1 and 3 .

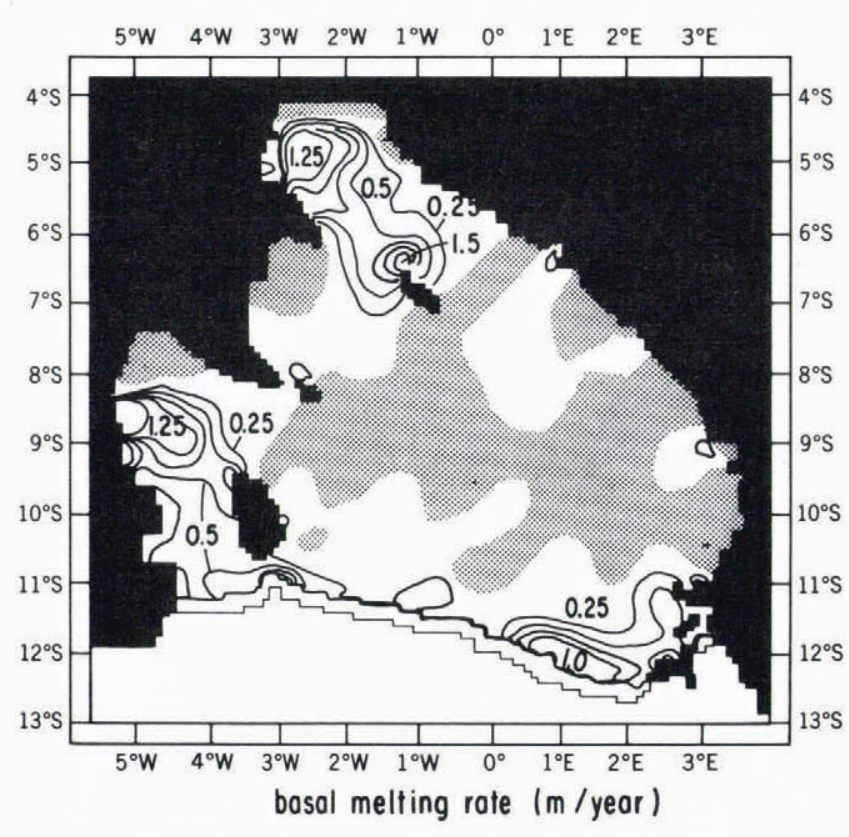

Fig. 7. The basal melting rate of Run 3 is contoured at intervals of $0.25 \mathrm{~m} /$ year (ice equivalent). The zero-melting contour is eliminated but regions of freezing are indicated by shading. 


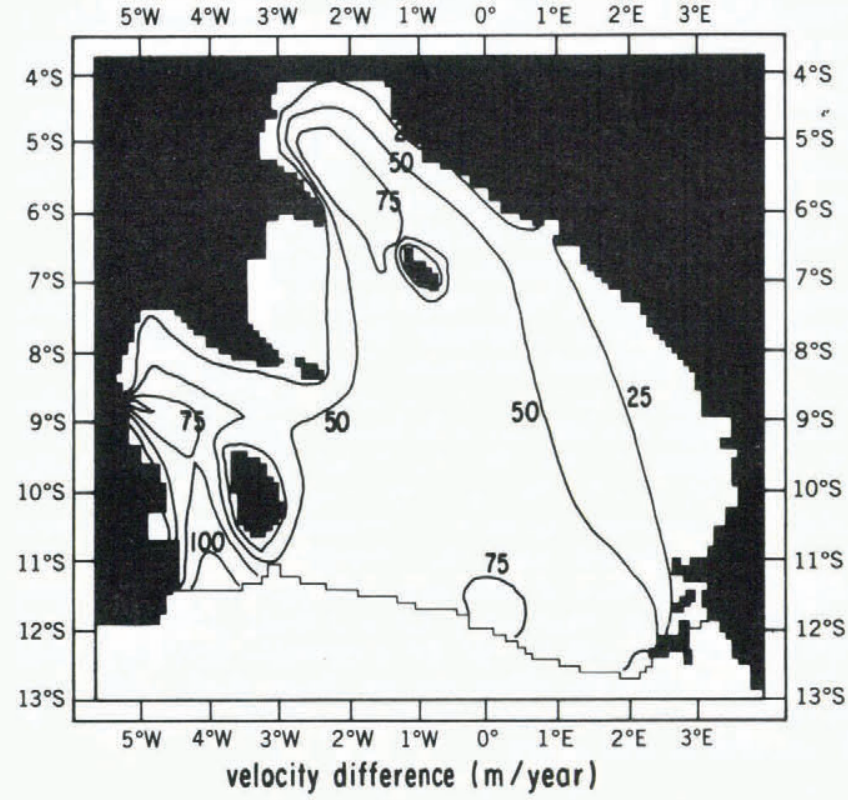

Fig. 8. The velocity magnitude difference between Run 1 and Run 3 is contoured at intervals of $25.0 \mathrm{~m} /$ year.

The comparison shown in Figure 8 indicates that the effect of basal melting is to reduce the simulated ice velocity up-stream of Crary Ice Rise by as much as $20 \%$ (see Fig. 5). This reduction results from the cooler depthaveraged temperature and the associated increased value of the depth-averaged flow-law parameter (denoted by $\bar{B}^{z}$ ). The distributions of $\bar{B}^{Z}$ for Runs 1 and 3 are shown in Figures 9 and 10, respectively.

The plot of $\bar{B}^{z}$ for Run 3 shown in Figure 10 demonstrates the effect of horizontal advection. High values of $\bar{B}^{z}$ are not simply localized in the zones of basal melting shown in Figure 7 but extend for a limited distance down-stream. The shading in Figure 10 delimits the zones of melting greater than $0.5 \mathrm{~m} / \mathrm{a}$. Lobes of high $\bar{B}^{z}$ are found to extend down-stream of these regions, particularly in the vicinity of Crary Ice Rise.

\section{COMPARISON WITH OBSERVATIONS}

The difference between the velocities of Run 1 and the observed values (see Thomas and others, 1984) is shown

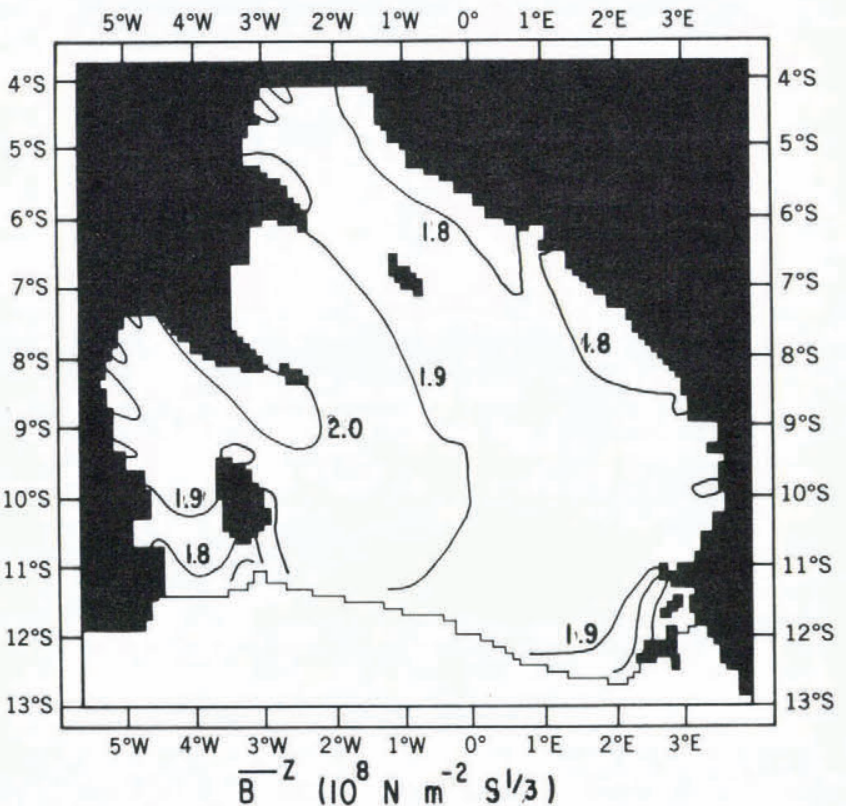

Fig. 9. The depth-averaged flow-law parameter $\left(B^{z}\right)$ of Run 1 is contoured at intervals of $10^{8}\left(\mathrm{~N} \mathrm{~m}^{-2} \mathrm{~s}^{1 / 3}\right)$.

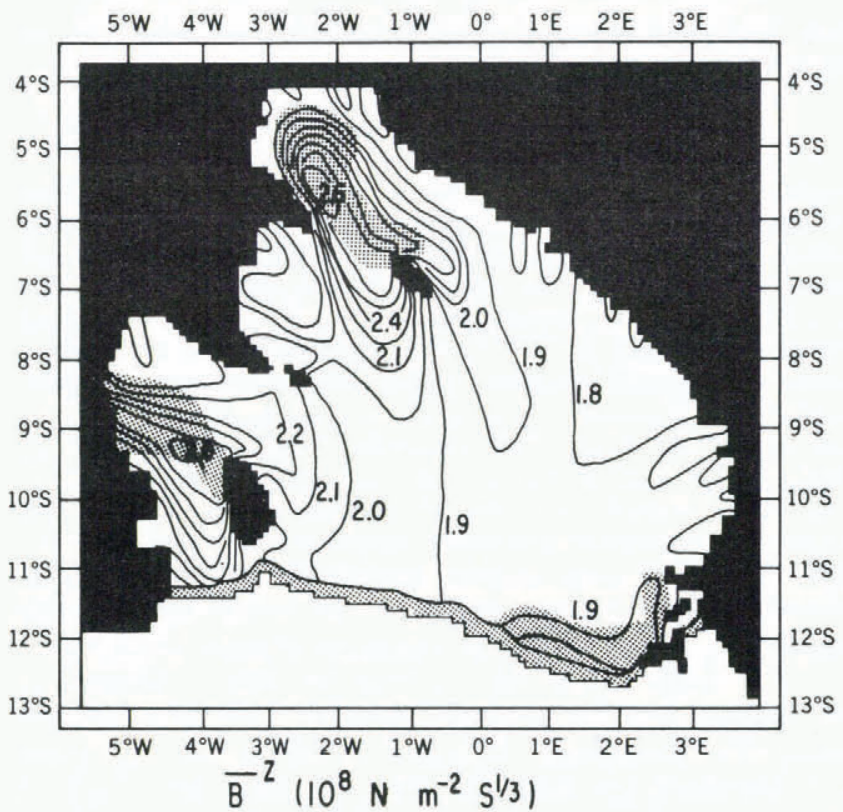

Fig. 10. The depth-averaged flow-law parameter $\left(\bar{B}^{z}\right)$ of Run 3 is contoured at intervals of $10^{8}\left(\mathrm{~N} \mathrm{~m}^{-2} \mathrm{~s}^{1 / 3}\right)$. Regions of basal melting in excess of $0.5 \mathrm{~m} /$ year are indicated by shading.

in Figure 11 scaled by the observed velocity magnitude. Figure 12 shows observed and simulated horizontal strain-rates. In general, agreement is good, with simulated velocities within $\pm 30 \%$ of observed values. The largest differences occur near the ice rises, and the results from Run 3 do not show any systematic improvement when compared with the observed values (Figs 8 and 11). Consequently, we cannot endorse either of the basal melting scenarios of Runs 1 or 3 as being "correct". We have, however, demonstrated that within the limits of our modeling capability both scenarios are plausible. Moreover, the significant differences between results from Runs 1 and 3 indicate that basal melting conditions have a major effect on ice-shelf deformation.

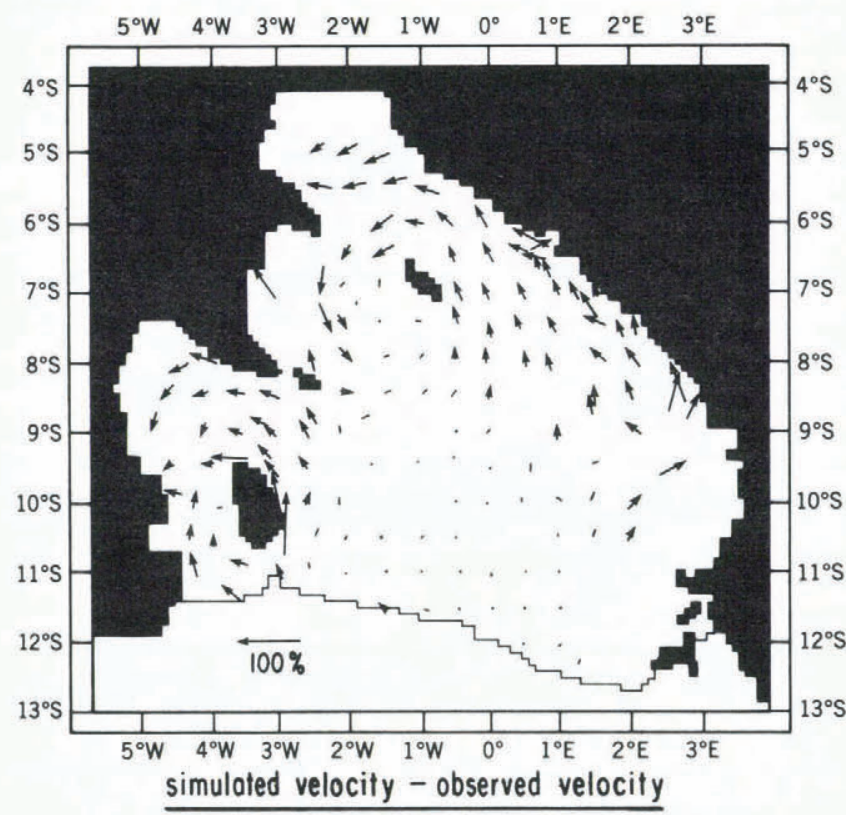

| observed velocity |

Fig. 11. The difference between the observed velocity and the simulated velocity of Run 1 , divided by the magnitude of the observed velocity, is plotted to display model performance (observations are taken from Thomas and others (1984)). 

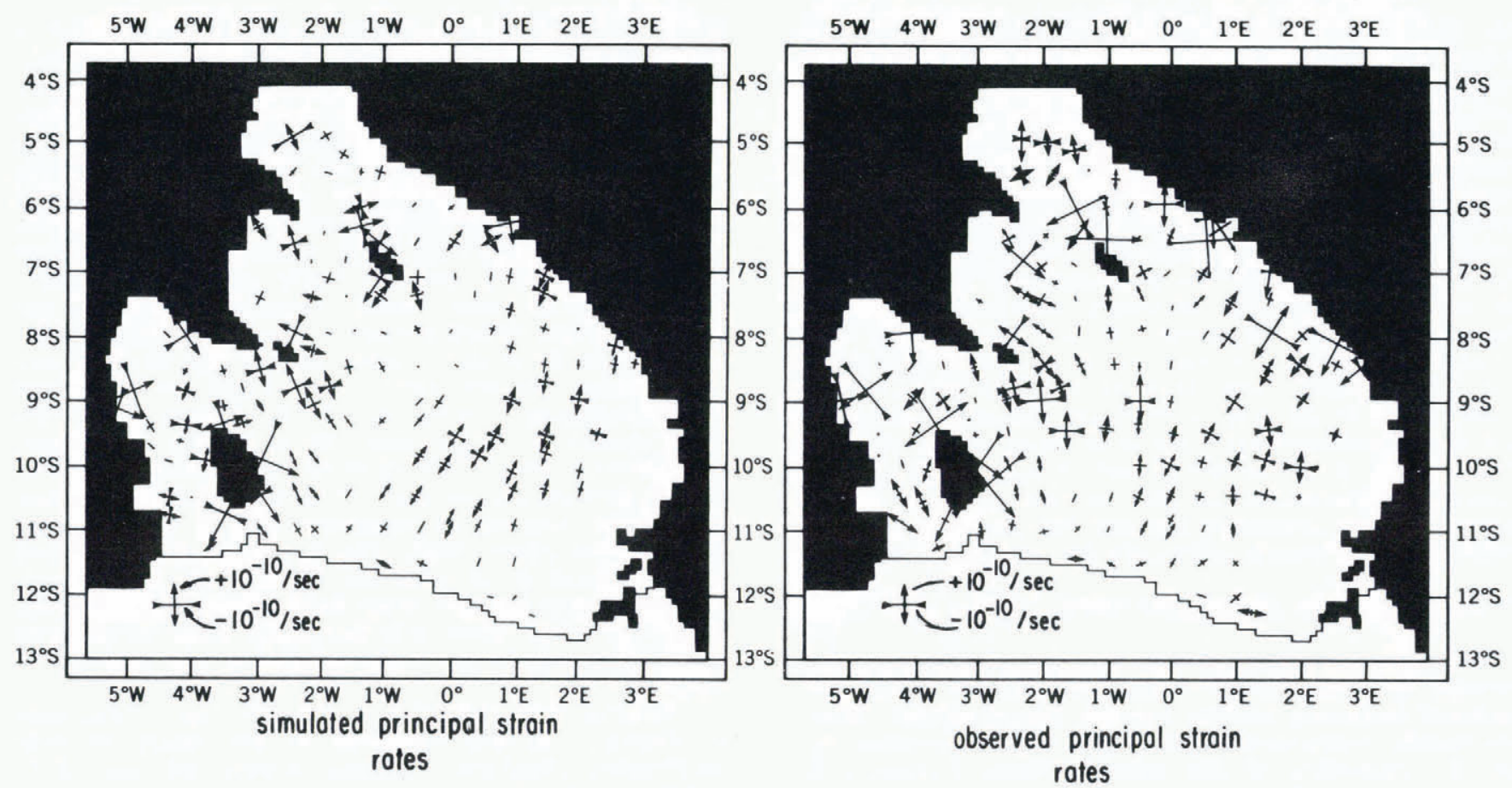

Fig. 12. The observed horizontal strain-rates (right figure) are represented by cross-like patterns denoting the orientation, magnitude, and sign of the principal components. The simulated horizontal strain-rates of Run 1 (left figure) are shown for comparison at the same approximate locations as where the observations were taken.

Three basic patterns associated with Crary Ice Rise, Roosevelt Island, and Byrd Glacier are apparent in the differences between the calculated and observed velocities and strain-rates. Figure 11 indicates that simulated outflow of ice stream B passes more to the east of Crary Ice Rise than it should. This error may be attributable to smaller, less distinct ice-shelf grounding zones to the east and south-east that were not represented in the simulation. These ice rises, visually observed by Bindschadler (personal communication; see also Thomas and Bentley, 1978) detected in radio echo-sounding data (Jezek, 1984; personal communication from S. Shabtaie) and evident in crevasse patterns (personal communication from A.P. Crary) may redirect the outflow of ice stream $B$ to the west of Crary Ice Rise.

Simulated ice velocities both to the east and to the south-west of Roosevelt Island are lower than observed (Fig. 11); simulated shear resistance at the margins of their channels is too large. We attribute this excessive resistance to (i) sub-mesh-scale processes such as crevassing, shear heating, and preferred fabric development that are not parameterized, and (ii) inadequate resolution.

Model error in simulating the outflow of Byrd Glacier is again representative of excessive resistance. On examining the simulated stress patterns, we found that excessive restraint in this case is maintained by tensile stresses exceeding $10^{5} \mathrm{~Pa}$ (1 bar) that couple the stagnant ice on either side of the outflow to the mountain walls. Field studies (Hughes, 1977; Brecher, 1982) indicate that these marginal shear zones are ruptured and therefore are incapable of transmitting tensile stress.

Bore-hole observations of temperature are too few and too widely spaced to resolve the general patterns of melting and freezing implied by our simulations. Figure 13 shows the comparison between computed and observed temperature-depth profiles at the two locations, J9 and Little America V (LAV), where bore holes have completely penetrated the ice shelf (Crary, 1961; Clough and Hansen, 1979). We remark that some discrepancy in this comparison is inevitable because of (i) mismatch between the actual ice thickness and the ice thickness used by the model (interpolated from RIGGS data to a $10 \mathrm{~km}$ grid, (ii) mismatch between the actual surface temperature and the surface temperature used by the model, and (iii) (in the case of J9) the tendency for the simulated flow to pass farther to the east of Crary Ice Rise than the observed flow. Nevertheless, the mismatch between the simulated and observed J9 temperature profile implies that the melting zone of Run 3 located up-stream of Crary Ice Rise is incorrect. If a time-independent basal melting zone actually exists up-stream of Crary Ice Rise, the J9 data will then restrict it to regions not previously traversed by the $\mathrm{J} 9$ ice column.

Observations of basal ice-layer composition indicate $6 \mathrm{~m}$ of basal sea ice at $\mathrm{J} 9$, and possibly thicker sea ice elsewhere (Neal, 1979; Zotikov and others, 1980; Jezek, 1984). Basal sea ice at J9 may seem inconsistent with the simulated basal melting pattern up-stream. Consideration of the heat fluxes that cause basal freezing, however, suggests

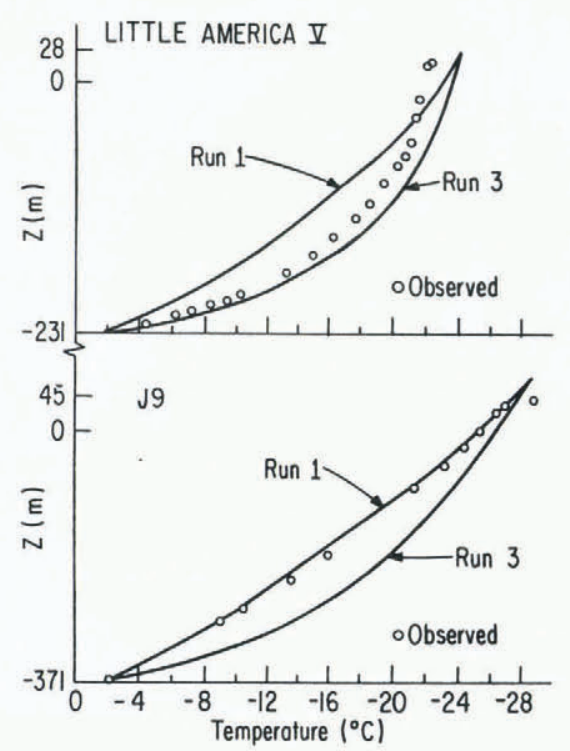

Fig. 13. The observed and simulated temperature-depth profiles at $\mathrm{J} 9$ and Little America $V$ are plotted for comparison (Crary, 1961; Clough and Hansen, 1979). 
that basal melting can actually amplify basal freezing at points down-stream. The factors to be considered are: (i) basal melting increases the vertical temperature gradient and upward heat flux in the basal ice layers (MacAyeal, unpublished [b]), (ii) increased upward heat flux does not diminish immediately when the ice column advects out of a basal melting area, and (iii) the increased upward heat-flux preconditions the ice column to strong basal freezing once it advects into regions where sensible heat is unavailable in the water column below. The enhancement of basal freezing by the thermal gradient steepening associated with basal melting must be considered in any interpretation of geophysical evidence for basal sea-ice accretions (MacAyeal and Thomas, 1979; Neal, 1979; Zotikov and others, 1980; Jezek, 1984). In the case of J9, where the sea-ice accretion and the temperature-depth profile are both known, there is little question as to the unlikelihood of strong basal melting up-stream. Observations of basal sea-ice accretions alone, however, cannot completely eliminate the possibility of basal melting in some regions sufficiently far up-stream.

\section{OCEANOGRAPHIC CONSIDERATIONS}

The simulated flow of Run 3 provides an approximate estimate of basal melting needed to maintain steady ice thickness (neglecting possible transient ice-rise effects). Here we examine oceanographic theory and field observations to test the plausibility of this estimate. Figure 7 presents $\dot{B}$ given by Run 3. The basic pattern suggests that there is a bi-modal melting regime: (i) melting in the remote parts of the cavity up-stream of Crary Ice Rise and Roosevelt Island, and (ii) melting in a strip along the ice front. Iceshelf draft patterns imply that these two categories should produce melt-water masses observed at different levels of the Ross Sea water column.

Hydrographic and isotopic observations conducted by Jacobs and others (1985) confirm that ice-shelf melt water occurs at two distinct depths in the open Ross Sea. The deepest melt water is called deep ice-shelf water (DISW) and results from contact between the ice shelf and dense high-salinity shelf water (HSSW), formed by winter sea-ice production north of the ice front (Gill, 1973; Killworth, 1974). Judging from its depth, DISW probably originates where the ice-shelf draft exceeds $400 \mathrm{~m}$ (indicated by shading in Figure 1). This draft requirement is satisfied by the regions of basal melting in Figure 7 up-stream of Crary Ice Rise and Roosevelt Island. The shallowest melt water is called shallow ice-shelf water (SISW) and is identified with

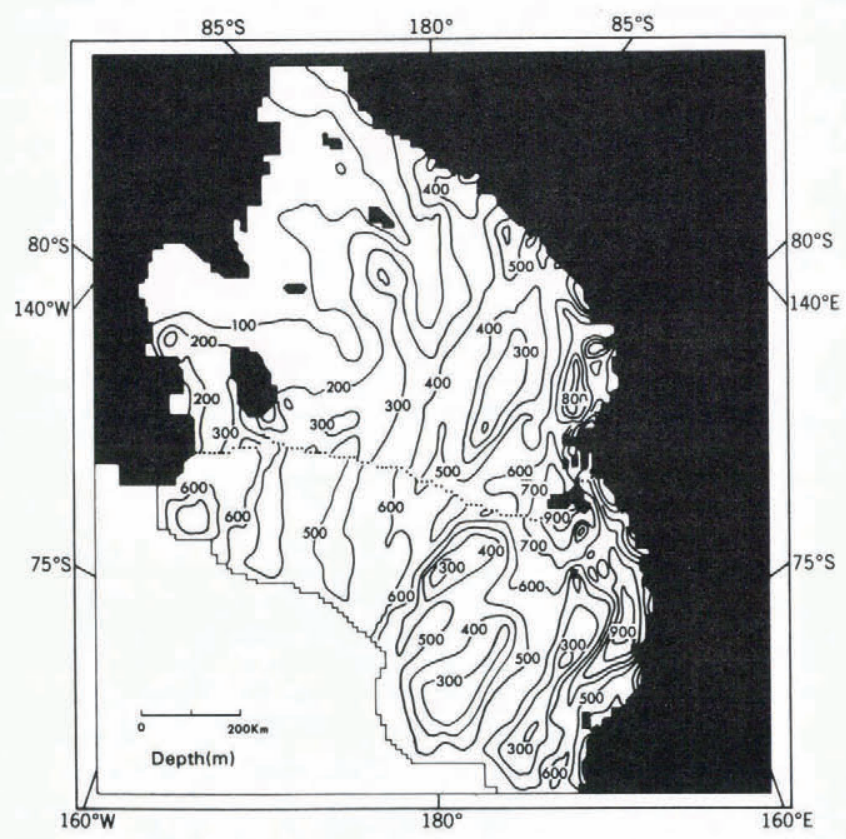

Fig. 14. The observed water-column thickness (depth) of the Ross Sea and sub-ice-shelf cavity (Greischar and Bentley, 1980). The dotted line denotes the ice-front position. basal melting along the ice-front areas in contact with a warm offshore water mass called the warm "core" (WMCO).

Possible DISW formation in the melting zone of Figure 7 up-stream of Crary Ice Rise is supported by the oceanographic theory of tidal-front formation (MacAyeal, 1984, 1985[a]). Figure 14 displays the water-column thickness (depth) in the sub-ice-shelf cavity. The reduced water-column thickness in the region up-stream of Crary Ice Rise and along the Siple Coast promotes efficient vertical mixing as a result of tidally generated turbulence. This mixing, in turn, erodes density stratification and promotes contact between relatively warm, but dense, HSSW and the ice. Observations taken through the $\mathrm{J} 9$ bore hole approximately $100 \mathrm{~km}$ north-east of Crary Ice Rise show that stratification does persist in the regions where the water column is thicker than $100 \mathrm{~m}$ (Jacobs and others, 1979; Foster, 1983). This observed stratification suppresses contact between the ice and the warm HSSW, and permits weak basal freezing as evidenced by the J9 ice core (Zotikov and others, 1980). The two vertically well-mixed layers observed at $\mathrm{J} 9$ near the ice and the sea bed do, however, extend through about $80 \mathrm{~m}$ of the water column. These two mixed layers will thus likely merge to eliminate stratification where the water column is less than $80 \mathrm{~m}$ thick.

Possible SISW formation in the ice-front melting zone of Figure 7 is also supported by the theory of tidal rectification (MacAyeal, 1985[b], unpublished [a]). Tidal rectification denotes the generation of time-independent circulation by periodic tidal currents passing across the depth discontinuity at the ice front (Zimmerman, 1981). A numerical simulation of tidal rectification in the Ross Sea indicates that oceanic heat advection into the cavity would be favored near Ross Island and near Roosevelt Island (MacAyeal, 1985[b]). Figure 15 displays the simulated oceanic advection patterns by showing the trajectories of imaginary passive tracers released along the ice front and near Steershead Ice Rise. Deepest penetration into the subice-shelf cavity after 7.5 years of tracer advection occurs near Ross Island and north-west of Roosevelt Island. The 7.5 years time period corresponds roughly to the geochemically derived sub-ice-shelf flushing time (Michel and others, 1979). The inability of trajectories to penetrate all regions of the sub-ice cavity indicates that tidal rectification alone

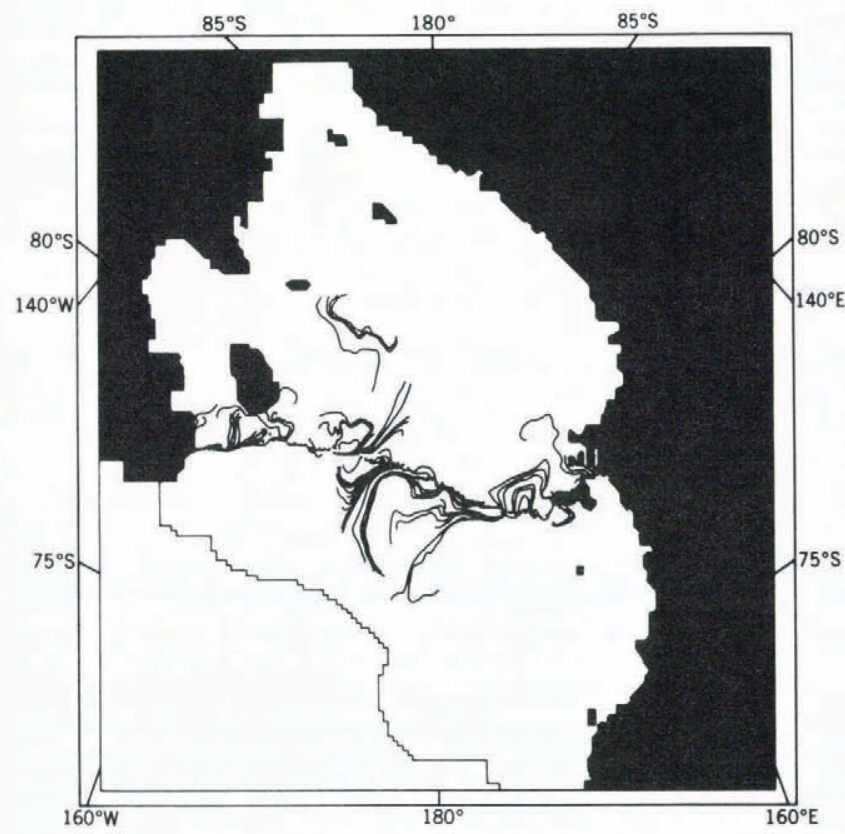

\subsection{YEARS}

Fig. 15. Simulated tracer trajectories emanating from the ice front and from a position near Steershead Ice Rise are plotted to represent oceanic ventilation of the sub-ice-shelf cavity after 7.5 years of advection. These streak lines were generated by a numerical simulation of tidal current rectification (MacAyeal, 1985[b], unpublished [a]). 
is insufficient to ventilate the cavity at the observed rate. An estimate of the heat flux associated with this simulated ventilation, however, is sufficient to explain the basal melting along the ice front derived in Run 3.

\section{CONCLUSION}

Our simulations have demonstrated that ice-shelf flow is thermodynamically coupled to basal ablation. This coupling was compared in two simulations of the present flow of the Ross Ice Shelf. In one simulation the basal melting rate was assumed zero everywhere, and in the other it was prescribed so that it would counterbalance the large-scale ice-thickening tendencies. The maximum flow difference between the two simulations was over $75 \mathrm{~m} /$ year in the region up-stream of Crary Ice Rise. Although this difference amounts to approximately $20 \%$ of the observed flow, it is not sufficient to explain discrepancies between the simulations and the observed flow, which are probably due to inadequate knowledge of the boundary conditions, sub-gridscale softening of marginal ice, and to our over-simplified choice of laboratory-derived flow-law parameters. Once these conditions and effects are better understood, diagnostic determination of prevailing basal melting conditions from comparisons between observed and simulated large-scale flow patterns may be possible for all of the major Antarctic ice shelves.

Our analysis indicates that the spatial pattern of basal melting required to maintain present ice-shelf thickness in steady state (except for possible transient ice-rise migration) is plausible. We cannot confirm, however, whether the magnitude of melting required to maintain steady state is also plausible. To determine the magnitude, direct measurement and/or vertical profiles of ice-shelf temperatures are required. The spatial distribution of melting derived from our analysis is also found to be qualitatively compatible with oceanographic theory and observations that suggest a bi-modal circulation. We suspect that deep traces of ice-shelf melt water found in the open Ross Sea originate up-stream of Crary Ice Rise or Roosevelt Island where our model indicates ice-flow convergence, and that shallow traces originate near the ice front.

\section{ACKNOWLEDGEMENTS}

We thank the Geophysical Fluid Dynamics Program of Princeton University for providing computer time and $\mathrm{Mr} P$. Tunison for drafting assistance. Ms G. York provided typing and editorial assistance. This research was supported by NSF DPP 84-01016.

\section{REFERENCES}

Barnes, P., and others. 1971. Friction and creep of polycrystalline ice, by P. Barnes, D. Tabor, and J.C.F. Walker. Proceedings of the Royal Society of London, Ser. A, Vol. 324, No. 1557, p. 127-55.

Bentley, C.R., and others. 1979. Ice-thickness patterns and the dynamics of the Ross Ice Shelf, Antarctica, by C.R. Bentley, J.W. Clough, K.C. Jezek, and S. Shabtaie. Journal of Glaciology, Vol. 24, No. 90, p. 287-94.

Brecher, H.H. 1982. Photogrammetric determination of surface velocities and elevations on Byrd Glacier. Antarctic Journal of the United States, Vol. 17, No. 5, p. 79-81.

Budd, W. 1966. The dynamics of the Amery Ice Shelf. Journal of Glaciology, Vol. 6, No. 45, p. 335-58.

Clough, J.W., and Hansen, B.L. 1979. The Ross Ice Shelf Project. Science, Vol. 203, No. 4379, p. 433-34.

Crary, A.P. 1961. Glaciological regime at Little America Station, Antarctica. Journal of Geophysical Research, Vol. 66 , No. 3, p. 871-78.

Foster, T.D. 1983. The temperature and salinity finestructure of the ocean under the Ross Ice Shelf. Journal of Geophysical Research, Vol. 88, No. C4, p. 2556-64.

Fujino, K., and others. 1974. The freezing point of seawater at pressures up to 100 bars, by K. Fujino, E.L. Lewis, and R.G. Perkins. Journal of Geophysical Research, Vol. 79 , No. 12 , p. $1792-97$
Gill, A.E. 1973. Circulation and bottom water production in the Weddell Sea. Deep-Sea Research, Vol. 20, No. 2, p. $111-40$.

Giovinetto, M., and others. 1966. The regime of the western part of the Ross Ice Shelf drainage system, by $M$. Giovinetto, E.S. Robinson, and C.W.M. Swithinbank. Journal of Glaciology, Vol. 6, No. 43, p. 55-68.

Glen, J.W. 1955. The creep of polycrystalline ice. Proceedings of the Royal Society of London, Ser. A, Vol. 228 , No. 1175 , p. 519-38.

Greischar, L.L., and Bentley, C.R. 1980. Isostatic equilibrium grounding line between the West Antarctic inland ice sheet and the Ross Ice Shelf. Nature, Vol. 283, No. 5748, p. 651-54.

Haltiner, G.L., and Williams, R.T. 1980. Numerical prediction and dynamic meteorology. New York, Wiley.

Hooke, R.L. 1981. Flow law for polycrystalline ice in glaciers: comparison of theoretical predictions, laboratory data, and field measurements. Reviews of Geophysics and Space Physics, Vol. 19, No. 4, p. 664-72.

Hooke, R.L., and others. 1979. Calculations of velocity and temperature in a polar glacier using the finite-element method, by R.L. Hooke, C.F. Raymond, R.L. Hotchkiss, and R.J. Gustafson. Journal of Glaciology, Vol. 24, No. 90 , p. $131-46$.

Hughes, T.J. 1975. The West Antarctic ice sheet: instability, disintegration, and initiation of ice ages. Reviews of Geophysics and Space Physics, Vol. 13, No. 4, p. 502-26.

Hughes, T.J. 1977. West Antarctic ice streams. Reviews of Geophysics and Space Physics, Vol. 15, No. 1, p. 1-46.

Jacobs, S.S., and others. 1979. Circulation and melting beneath the Ross Ice Shelf, by S.S. Jacobs, A.L. Gordon, and J.L. Ardai, jr. Science, Vol. 203, No. 4379, p. 39-43.

Jacobs, S.S., and others. 1985. Origin and evolution of water masses near the Antarctic continental margin: evidence from $\mathrm{H}_{2}{ }^{18} \mathrm{O} / \mathrm{H}_{2}{ }^{16} \mathrm{O}$ ratios, by S.S. Jacobs, R.G. Fairbanks, and Y. Horibe. (In Jacobs, S.S., ed. Oceanology of the Antarctic continental shelf. Washington, DC, American Geophysical Union, p. 59-86. (Antarctic Research Series, Vol. 43.))

Jaeger, J.C., and Cook, N.G.W. 1976. Fundamentals of rock mechanics. London, Chapman and Hall.

Jezek, K.C. 1984. Recent changes in the dynamic condition of the Ross Ice Shelf, Antarctica. Journal of Geophysical Research, Vol. 89, No. B1, p. 409-16.

Killworth, P.D. 1974. A baroclinic model of motions on Antarctic continental shelves. Deep-Sea Research, Vol. 21, No. 10 , p. 815-37.

Kirchner, J.F., and others. 1979. Lateral density differences from seismic measurements at a site on the Ross Ice Shelf, Antarctica, by J.F. Kirchner, C.R. Bentley, and J.D. Robertson. Journal of Glaciology, Vol. 24, No. 90, p. 309-12.

MacAyeal, D.R. 1984. Thermohaline circulation below the Ross Ice Shelf: a consequence of tidally induced vertical mixing and basal melting. Journal of Geophysical Research, Vol. 89, No. C1, p. 597-606.

MacAyeal, D.R. 1985[a]. Evolution of tidally triggered meltwater plumes below ice shelves. (In Jacobs, S.S., ed. Oceanology of the Antarctic continental shelf. Washington, DC, American Geophysical Union, p. 133-43. (Antarctic Research Series, Vol. 43.))

MacAyeal, D.R. 1985[b]. Tidal rectification below the Ross Ice Shelf, Antarctica. (In Jacobs, S.S., ed. Oceanology of the Antarctic continental shelf. Washington, DC, American Geophysical Union, p. 109-32. (Antarctic Research Series, Vol. 43.))

MacAyeal, D.R. Unpublished[a]. Tidal-current rectification and tidal mixing fronts: controls on the Ross Ice Shelf flow and mass balance. [Ph.D. thesis, Princeton University, 1983.]

MacAyeal, D.R. Unpublished[b]. Transient temperature-depth profiles of the Ross Ice Shelf. [M.Sc. thesis, University of Maine at Orono, 1979.] 
MacAyeal, D.R., and Thomas, R.H. 1979. Ross Ice Shelf temperatures support a history of ice-shelf thickening. Nature, Vol. 282, No. 5740, p. 703-05.

MacAyeal, D.R., and Thomas, R.H. 1982. Numerical modeling of ice-shelf motion. Annals of Glaciology, Vol. 3, p. 189-94.

Mahaffy, M.W. 1976. A three-dimensional numerical model of ice sheets: tests on the Barnes Ice Cap, Northwest Territories. Journal of Geophysical Research, Vol. 81, No. 6, p. 1059-66.

Manabe, S., and Bryan, K. 1969. Climate calculations with a combined ocean-atmosphere model. Journal of the Atmospheric Sciences, Vol. 26, No. 4, p. 786-89.

Michel, R.L., and others. 1979. Tritium and carbon-14 distributions in seawater from under the Ross Ice Shelf Project ice hole, by R.L. Michel, T.W. Linick, and P.M. Williams. Science, Vol. 203, No. 4379, p. 445-46.

Neal, C.S. 1979. The dynamics of the Ross Ice Shelf revealed by radio echo-sounding. Journal of Glaciology, Vol. 24, No. 90, p. 295-307.

Paterson, W.S.B. 1969. The physics of glaciers. Oxford, etc., Pergamon Press.

Pinder, G.F., and Gray, W.G. 1977. Finite element simulation in surface and subsurface hydrology. New York, Academic Press.

Robin, G. de Q. 1975. Ice shelves and ice flow. Nature, Vol. 253 , No. 5488 , p. $168-72$.

Sanderson, T.J.O. 1979. Equilibrium profile of ice shelves. Journal of Glaciology, Vol. 22, No. 88, p. 435-60.

Sanderson, T.J.O., and Doake, C.S.M. 1979. Is vertical shear in an ice shelf negligible? Journal of Glaciology, Vol. 22, No. 87 , p. $285-92$.

Schey, H.M. 1973. Div. Grad. curl and all that. New York, W.W. Norton \& Co.

Shabtaie, S., and Bentley, C.R. 1979. Investigation of bottom mass-balance rates by electrical resistivity soundings on the Ross Ice Shelf, Antarctica. Journal of Glaciology, Vol. 24 , No. 90 , p. $331-43$.

Swithinbank, C.W.M. 1963. Ice movement of valley glaciers flowing into the Ross Ice Shelf, Antarctica. Science, Vol. 141 , No. 3580 , p. $523-24$.

Swithinbank, C.W.M., and Zumberge, J.H. 1965. The ice shelves. (In Hatherton, T., ed. Antarctica. New York, Frederick A. Praeger, p. 199-220.)

Thomas, R.H. 1973. The creep of ice shelves: interpretation of observed behaviour. Journal of Glaciology, Vol. 12, No. 64 , p. 55-70.

Thomas, R.H. 1979. The dynamics of marine ice sheets. Journal of Glaciology, Vol. 24, No. 90, p. 167-77.

Thomas, R.H., and Bentley, C.R. 1978. The equilibrium state of the eastern half of the Ross Ice Shelf. Journal of Glaciology, Vol. 20, No. 84, p. 509-18.

Thomas, R.H., and MacAyeal, D.R. 1982. Derived characteristics of the Ross Ice Shelf, Antarctica. Journal of Glaciology, Vol. 28, No. 100, p. 397-412.

Thomas, R.H., and others. 1984. Glaciological studies on the Ross Ice Shelf, Antarctica, 1973-1978, by R.H. Thomas, D.R. MacAyeal, D.H. Eilers, and D.R. Gaylord. (In Hayes, D., and Bentley, C.R., ed. The Ross Ice Shelf: glaciology and geophysics. Washington, DC, American Geophysical Union, p. 21-53. (Antarctic Research Series, Vol. 42.))

Weast, R.C., ed. 1968. Handbook of chemistry and physics. 49 th edition. Cleveland, Chemical Rubber Co.

Weertman, J. 1957. Deformation of floating ice shelves. Journal of Glaciology, Vol. 3, No. 21, p. 38-42.

Weller, G.E., and Schwerdtfeger, P. 1971. New data on the thermal conductivity of natural snow. Journal of Glaciology, Vol. 10, No. 59, p. 309-11.

Young, N.W. 1981. Responses of ice sheets to environmental changes. [Union Géodésique et Géophysique Internationale. Association Internationale des Sciences Hydrologiques.] Sea level, ice and climatic change. Proceedings of the symposium held 7-8 December 1979 during the 17 th general assembly of the International Union of Geodesy and Geophysics, Canberra, p. 331-60. (IAHS Publication No. 131.)

Zimmerman, J.T.F. 1981. Dynamics, diffusion and geomorphological significance of tidal residual eddies. Nature, Vol. 290 , No. 5807, p. 549-55.
Zotikov, I.A., and others. 1980. Core drilling through the Ross Ice Shelf (Antarctica) confirmed basal freezing, by I.A. Zotikov, V.S. Zagorodnov, and Ju. V. Raikovsky [i.e. Yu. V. Raykovskiy]. Science, Vol. 207, No. 4438, p. 1463-65.

Zumberge, J.H. 1964. Horizontal strain and absolute movement of the Ross Ice Shelf between Ross Island and Roosevelt Island, Antarctica, 1958-1963. (In Mellor, M., ed. Antarctic snow and ice studies. Washington, DC, American Geophysical Union, p. 65-81. (Antarctic Research Series, Vol. 2.))

\section{APPENDIX A}

\section{A SIMPLE EXAMPLE}

Complex numerical simulations can sometimes obscure the underlying physics. We, therefore, consider as an illustrative example, idealized ice-shelf flow down a frictionless, parallel-sided channel to determine the effects of basal melting on steady-state thickness distribution. Sanderson (1979), in a similar study, found that spatially uniform basal melting produces a thinner, slower-moving ice shelf with a steeper down-stream thickness gradient. The influence of basal melting on ice-shelf temperature was not considered by Sanderson (1979). Here we couple the heat-transfer problem with the analytic ice-flow equations by adopting the Lagrangian point of view described below.

The steady-state thickness and flow of the ideal ice shelf are assumed uniform across the channel width, and are determined by monitoring the thickness, temperature distribution, and down-stream position of a marked ice column. The ice-column thickness is given by:

$$
\frac{\mathrm{d} H}{\mathrm{~d} t}=-\dot{\epsilon} H+\dot{B}
$$

where

$H$ ice-column thickness,

$\dot{B}$ basal accumulation rate acting on the ice column (m of ice/s; negative for melting),

द unidirectional horizontal spreading rate at the position of the ice column

where

$$
\dot{\epsilon}=\left[\rho_{\mathrm{i}} g / 4 \bar{B}^{z}\left[1-\frac{\rho_{\mathrm{i}}}{\rho_{\mathrm{W}}}\right] H\right]^{3} \text { (Weertman, 1957), }
$$

and

$$
\begin{aligned}
& \rho_{\mathrm{i}} \text { density of pure ice }\left(917.0 \mathrm{~kg} / \mathrm{m}^{3}\right) \text {, } \\
& \rho_{\mathrm{W}} \text { density of sea-water }\left(1028 \mathrm{~kg} / \mathrm{m}^{3}\right) \text {, } \\
& \bar{B}^{z} \text { vertical average of } B .
\end{aligned}
$$

The temperature-depth profile of the ice column determines $\bar{B}^{z}$ and is given by the one-dimensional heat equation written in terms of a stretched vertical coordinate $\zeta$ (equal to 0 at the ice-shelf surface and 1 at the ice-shelf base) (see Appendix B):

$$
\frac{\partial \theta}{\partial t}=\frac{\kappa}{H^{2}} \frac{\partial^{2} \theta}{\partial \zeta^{2}}+\frac{\dot{B \zeta}}{H} \frac{\partial \theta}{\partial \zeta} .
$$

The last term on the right-hand side of Equation (A3) represents coordinate "stretching" caused by basal accumulation (snow-accumulation is assumed zero in this example). The boundary and initial $(t=0)$ conditions are chosen to represent the typical Antarctic environment (the effect of 
pressure and salinity on the freezing point is disregarded in this example):

$$
\begin{gathered}
\theta(0, t)=-30^{\circ} \mathrm{C}, \\
\theta(1, t)=-2.2^{\circ} \mathrm{C}, \\
\theta(\zeta, t=0)=-30^{\circ} \mathrm{C}+\left(27.8^{\circ} \mathrm{C}\right) \zeta .
\end{gathered}
$$

Solving Equations (A1) through (A6) gives $H(t)$ as a function of time for an individual ice column. To convert this information into an ice-shelf thickness profile, the down-stream displacement of the ice column from the grounding line, $x(t)$, must also be determined. The equation for $x(t)$ is

$$
x(t)=\int_{0}^{t}\left[\int_{0}^{x(t)} \epsilon \mathrm{d} s+V_{0}\right) \mathrm{d} t
$$

where $V_{0}=200 \mathrm{~m} /$ year is the prescribed horizontal velocity at the grounding line $(x=0)$.

Equations (A1) through (A7) were solved for $H(x)$ under a variety of basal meiting scenarios using straightforward finite-difference methods. Figure 16 summarizes the results. Curves labeled A represent ice-shelf conditions resulting from zero basal melting. Curves labeled B represent spatially uniform basal melting. For curves $C$ and D, $5 \mathrm{~m} / \mathrm{a}$ melting and freezing, respectively, were applied to the ice column during the first 25 years after it crossed the grounding line (within approximately $7 \mathrm{~km}$ of the grounding line). After this initial time period, zero melting or freezing was applied to both curves C and D. A specific time period was chosen to represent the limits of basal ablation of curves $C$ and $D$ so that the two ice columns of each example have an equal amount of ice added or subtracted by basal processes.

As expected from Sanderson's (1979) analysis of spatially uniform melting conditions, the ice thickness displayed by curve $B$ is everywhere reduced and the travel time required to traverse the length of the flow line is considerably longer. Sanderson's (1979) results do not completely describe conditions expected with non-uniform basal melting, however, because thermal effects were disregarded. The present analysis shows that ice-thickness profiles for three widely different basal melting scenarios (curves A, C, and D) can be surprisingly similar. Curves A, C, and D indicate nearly the same thickness down-stream of $x=30 \mathrm{~km}$; yet curve A results from zero basal melting and curves $C$ and $D$ result from $5 \mathrm{~m} /$ year melting and freezing, respectively, near the grounding line.

An explanation of this similarity is provided by the plots of the temperature-dependent flow-law parameter $\bar{B} z$ shown in Figure 3 . For curves $\mathrm{C}$ and $\mathrm{D}$, initial melting or freezing cause $\bar{B}^{z}$ to change by approximately $20 \%$. Downstream of the isolated melting or freezing zones, the temperature-depth profiles re-adjust towards their original conductive equilibrium. This re-adjustment is sufficiently slow, however, that creep-thinning rates are influenced over the entire ice-shelf length. Creep-thinning rates associated
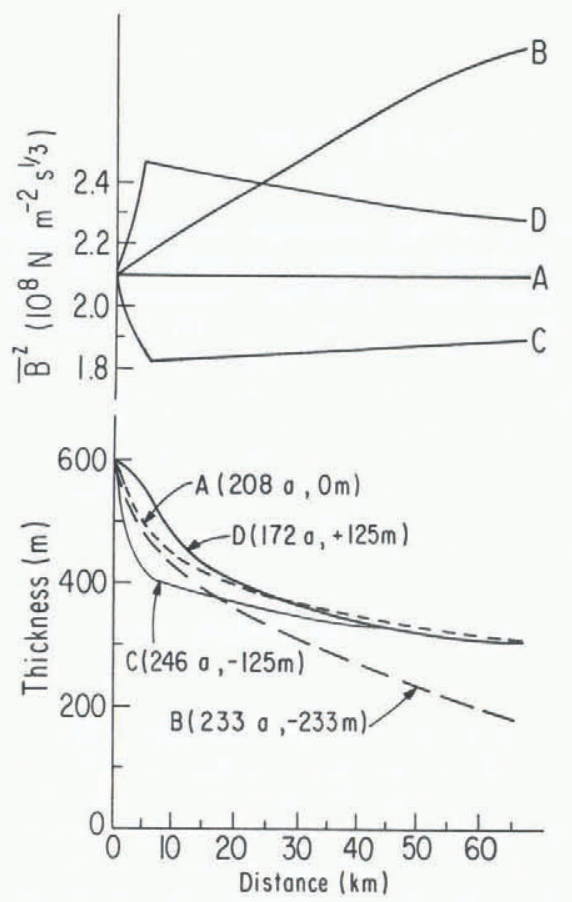

Fig. 16. Ice thickness and $\bar{B} z$ are plotted as a function of distance down-stream from the grounding line for four ice shelves confined by frictionless, parallel-sided channels and experiencing different basal melting conditions. For reference, the effect of zero basal melting is displayed by curves labeled A. B represents the effect of spatially uniform basal melting at a rate of $1 \mathrm{~m} /$ year. Curves $\mathrm{C}$ and D represent the effects of basal melting and freezing. respectively, at the rates of $\pm 5 \mathrm{~m} /$ year, applied for the first 25 years after the ice columns cross the grounding lines. The times required in years for an ice column to traverse the ice shelves are indicated at the right of the curve labels.

with high $\bar{B}^{z}$ (curve D) are sufficiently greater than those associated with low $\bar{B}^{z}$ (curve c) that the ice-column thicknesses of curves C and D eventually converge despite the initial basal ablation or accumulation.

\section{APPENDIX B}

\section{NUMERICAL TREATMENT OF THE MOMENTUM
BALANCE}

Equation (1) is rendered into a suitable form for finite-element analysis by applying the method of weighted residuals (Pinder and Gray, 1977), by applying the divergence theorem (Schey, 1973), and by formally integrating over depth. The result is an equation that expresses the gross mechanical energy budget describing the conversion of gravitational potential energy into heat energy by viscous dissipation:

$$
\begin{aligned}
& \iint_{A} 4\langle\nu\rangle_{z}\left\{\delta \dot{\epsilon}_{x x} \dot{\epsilon}_{x x}+\delta \dot{\epsilon}_{y y} \dot{\epsilon}_{y y}+\dot{\delta \epsilon} x \dot{\epsilon}_{x y}+\frac{1}{2} \delta \dot{\epsilon}_{x x} \dot{\epsilon}_{y y}+\frac{1}{2} \delta \dot{\epsilon}_{y y} \dot{\epsilon}_{x x}\right\} \mathrm{d} x \mathrm{~d} y \\
& =\iint_{A}\left[\frac{g}{\rho_{\mathrm{W}}}\langle\rho\rangle_{z}{ }^{2}\left(\dot{\delta \epsilon_{x x}}+\delta \dot{\epsilon}_{y y}\right)+\frac{g}{\rho_{\mathrm{W}}}\langle\rho\rangle_{z} \nabla_{\mathrm{H}}\langle\rho\rangle_{z} \cdot \delta u-g\langle\rho z\rangle_{z}\left(\delta \dot{\epsilon}_{x x}+\delta \dot{\epsilon}_{y y}\right)\right] \mathrm{d} x \mathrm{~d} y \\
& -\int_{s_{1}} \frac{1}{2} g / \rho_{\mathrm{w}}\langle\rho\rangle_{z}^{2} \delta u \cdot n_{1} \mathrm{~d} l \\
& -\int_{S_{2}} \delta u \cdot\langle\sigma\rangle_{z} \cdot n_{2} \mathrm{~d} \ell
\end{aligned}
$$


where

$$
<\cdot\rangle_{z}=\int_{z_{\mathrm{b}}}^{z_{\mathrm{s}}} \cdot \mathrm{d} z
$$

and where $z_{\mathrm{s}}$ is the elevation of the ice-shelf surface $\left(z=0\right.$ at sea-level, positive upwards), $z_{\mathrm{b}}$ is the elevation of the ice-shelf base, $A$ is the projection of the ice-shelf area in the horizontal plane, $s_{1}$ and $s_{2}$ are the contours defining the ice front and the coastlines, respectively, and $n_{1}$ and $n_{2}$ are vector units perpendicular to $s_{1}$ and $s_{2}$ (pointing away from the ice shelf). The density-depth profile appearing in Equation (B1) was obtained by fitting an exponential function to the observed profile at $\mathrm{J} 9$ on the Ross Ice Shelf (Kirchner and others, 1979). This exponential function is:

$$
\rho(z)=917.0-608.0 \exp \left\{-0.043\left(z_{\mathrm{s}}-z\right)\right\}
$$

A physical interpretation of Equation (B1) has been presented in MacAyeal and Thomas (1982) and may be summarized as follows. The term on the left-hand side of the equation represents the conversion of mechanical energy into heat energy by viscous dissipation. The terms appearing on the right-hand side represent, in the order of their appearance: (i) work done against hydrostatic sea pressure by the vertical motion of the ice-shelf base, (ii) work done against hydrostatic sea pressure by the horizontal motion of the sloping ice-shelf base, (iii) work done against gravity to vertically redistribute ice mass, (iv) work done against hydrostatic sea pressure by the horizontal motion of the ice front, and (v) work done against stresses at the sides of the ice shelf. All vertical motions are expressed in terms of horizontal motions through the use of the incompressibility condition:

$$
\dot{\boldsymbol{\epsilon}}_{z z}=-\dot{\boldsymbol{\epsilon}}_{x x}-\dot{\boldsymbol{\epsilon}}_{y y}
$$

This incompressibility condition disregards the firndensification process which is uncoupled from ice-shelf deformation.

To solve Equation (B1) within a given numerical domain and for a given ice-thickness distribution, standard finite-element procedures are adapted (Pinder and Gray, 1977). The numerical domain is broken into quadrilateral area elements and Lagrangian basis functions are used to represent the variation of $H, u, \delta u,\langle\rho\rangle_{z}$, and $\langle\rho z\rangle_{z}$ within each element ( $\nu$ is assumed constant within each element). These basis functions are written:

$$
\Psi_{l}(\xi, \eta)= \begin{cases}t(1+\xi)(1-\eta) & \ell=1, \\ \downarrow(1+\xi)(1+\eta) & \ell=2, \\ t(1-\xi)(1+\eta) & \ell=3, \\ t(1-\xi)(1-\eta) & \ell=4\end{cases}
$$

where $\xi(x, y)$ and $\eta(x, y)$ are local curvilinear coordinates ranging between 1 and -1 , and $\ell$ is an index that labels the corners $\left(x_{1}, y_{2}\right)$, or nodes, of the quadrilateral element. Each $\psi_{l}$ will be 1 at the $l$ th node and zero at the three other nodes. In addition, each $\psi_{1}$ varies linearly along the curvilinear edges of the element and quadratically along the curvilinear diagonal of the element. To accommodate irregular nodal spacing, $x$ and $y$ within each element are expressed as functions of $\xi$ and $\eta$ according to the following isoparametric approximation:

$$
\begin{aligned}
& x(\xi, \eta)=\underset{k}{\sum_{k}} \boldsymbol{x}_{k}(\xi, \eta), \\
& y(\xi, \eta)=\underset{k}{\sum_{k}} \boldsymbol{y}_{k} \psi_{k}(\xi, \eta) .
\end{aligned}
$$

An arbitrary function $f(x, y)$ and its derivatives will be expressed within each element as follows

$$
f(x, y)=\sum_{\ell=1}^{4} f_{l} \psi_{\ell}(\xi(x, y), \eta(x, y)),
$$

$$
\frac{\partial}{\partial x} f(x, y)=\sum_{\ell=1}^{4} f_{\ell}\left[\frac{\partial y}{\partial \eta} \frac{\partial \psi_{\ell}}{\partial \xi}-\frac{\partial y}{\partial \xi} \frac{\partial \psi_{\ell}}{\partial \eta}\right] /\left(\frac{\partial x}{\partial \xi} \frac{\partial y}{\partial \eta}-\frac{\partial x}{\partial \eta} \frac{\partial y}{\partial \xi}\right),
$$

and

$$
\frac{\partial}{\partial y} f(x, y)=\sum_{\ell=1}^{4} f_{\ell}\left[-\frac{\partial x}{\partial \eta} \frac{\partial \psi_{\ell}}{\partial \xi}+\frac{\partial x}{\partial \xi} \frac{\partial \psi_{\ell}}{\partial \eta}\right] /\left(\frac{\partial x}{\partial \xi} \frac{\partial y}{\partial \eta}-\frac{\partial x}{\partial \eta} \frac{\partial y}{\partial \xi}\right)
$$

where $f_{\ell}$ is the value of $f(x, y)$ at the nodal position $\left(x_{\ell}, y_{\ell}\right)$. We remark that the benefits derived from using irregular nodal spacing do not always outweigh the associated increase in computational effort. In the present study, we chose to adopt regular spacing because inadequate boundary conditions would likely mask any possible improvements associated with grid refinement.

After substituting the finite-element representations of $H, u, \delta u,\langle\rho\rangle_{z}$, and $\left\langle\rho_{z}\right\rangle_{z}$ given by Equations (B7) through (B9) into Equation (B1), all area integrals may be performed by direct analysis or by numerical quadrature. The result is a purely algebraic constraint on the unknown nodal values of $u_{\ell}$ and $\delta u_{\ell}$. This algebraic constraint is further reduced into a system of $2 N$ linear equations where $N$ is the total number of nodes in the domain, by requiring that $\delta u_{\ell}$ be completely arbitrary. For those nodal values of $u$ specified by boundary conditions, appropriate equations of the $2 N$ system are eliminated.

To satisfy the non-linear relationship between \langle\rangle$_{z}$ and $\epsilon$ expressed by Equations (4) and (5), we adopt an iterative convergence technique. Initially, we guess a viscosity distribution labeled \langle\rangle$_{z}{ }^{\circ}$. After solving the linear system of equations determined from Equation (B1) for $\boldsymbol{u}^{\circ}$ and $\dot{\boldsymbol{\epsilon}}^{\circ}$, we correct the viscosity distribution according to

$$
\langle v\rangle_{z}^{1}=\left\langle\frac{\mathrm{B}}{2\left|\left(\dot{\epsilon}^{\circ}\right)^{2}\right|^{1 / 3}}>z\right.
$$

After iterating ten times according to the pattern shown in Equation (B10), a Newton-Raphson technique is adopted to speed convergence

$$
\begin{aligned}
\langle v\rangle_{z}^{k+1} & =\langle v\rangle_{z}^{k}-\alpha\left[\langle v\rangle_{z}^{k}-<\frac{B}{2\left|\left(\dot{\epsilon}^{k}\right)^{2}\right|^{1 / 3}}>z\right], \\
& \cdot\left[\langle v\rangle_{z}^{k}-\langle v\rangle_{z}^{k-1}\right] /\left[\langle v\rangle_{z}^{k}-\left\langle\frac{B}{2\left|\left(\dot{\epsilon}^{k}\right)^{2}\right|^{1 / 3}}>z,\right.\right. \\
& \left.-<v\rangle_{z}^{k-1}+<\frac{B}{2\left|\left(\dot{\epsilon}^{k-1}\right)^{2}\right|^{1 / 3}}>z\right]
\end{aligned}
$$

where $\alpha=1.1$ is a convergence acceleration factor. Equation (B11) is an improvement over Equation (B10) once convergence begins because viscosity updates are based on the derivative of the prior viscosity estimates with respect to the prior error in satisfying Equation (4). Typically, about 30 iterations are required to reduce viscosity errors below the $0.5 \%$ level deemed acceptable in this study.

To solve the system of diagonally dominant linear algebraic equations resulting from the finite-element 
discretization of Equation (B1), we adopted a block relaxation procedure. This procedure is iterative but is found to require less computer time and memory than the conventional direct-solution procedure consisting of upper triangularization and back substitution of a "banded" stiffness matrix. Our iterative procedure is based on the alternate-direction implicit (ADI) method first used in icesheet modeling by Mahaffy (1976). Despite possible irregular nodal placement, we designed the numerical domain so that each node could be labeled by indices $i$ and $j$ which represent the rows and columns of a global rectangular array. The system of linear equations generated by Equation (B1) may thus be represented in a manner that exploits the $(i, j)$-labeling of the nodal variables:

$$
\begin{aligned}
& \boldsymbol{I}_{i j} \boldsymbol{u}_{i j}+A_{i j} \boldsymbol{u}_{i+1, j}+\boldsymbol{B}_{i j} \boldsymbol{\mu}_{i+1, j+1}+\mathrm{C}_{i j} u_{i, j+1}+ \\
+ & \boldsymbol{D}_{i j u_{i-1, j+1}}+\boldsymbol{E}_{i j} \boldsymbol{u}_{i-1, j}+\boldsymbol{F}_{i j} \boldsymbol{u}_{i-1, j-1,}+\boldsymbol{G}_{i j} \boldsymbol{u}_{i, j-1}+ \\
+ & \boldsymbol{H}_{i j \boldsymbol{u}_{i+1, j-1}}=\boldsymbol{F}_{i j} .
\end{aligned}
$$

Here each $\boldsymbol{I}_{i j}$ through $\boldsymbol{H}_{i j}$ is a $2 \times 2$ matrix, and $\boldsymbol{F}_{i j}$ is a column vector, composed of constants derived from the integration of the basis functions and their derivatives over the element areas. Equation (B12) is partitioned into a pair of equivalent equations that are easier to solve computationally and that generate a sequence of interim nodal velocities $u_{i j}{ }^{m}$ that converge to the exact solution:

$$
\begin{aligned}
& \left\{I_{i j} u_{i j}^{m+1}+A_{i j} u_{i+1, j}^{m+1}+E_{i j}{ }^{m+1}{ }_{i-1, j}^{m+1}\right\}= \\
& =-B_{i j} u_{i+1, j+1}^{m}-C_{i j} \stackrel{m}{u_{i-1, j+1}}-D_{i j} \boldsymbol{u}_{i-1, j+1}^{m}- \\
& -\boldsymbol{F}_{i j} \boldsymbol{u}_{i-1, j-1}^{m}-\boldsymbol{G}_{i j} \boldsymbol{u}_{i, j-1}^{m}-\boldsymbol{H}_{i j} \boldsymbol{u}_{i+1, j-1}^{m}+\boldsymbol{F}_{i j}
\end{aligned}
$$

and

$$
\begin{aligned}
& \left\{I_{i j} u_{i, j}^{n+1}+C_{i j} u_{i, j+1}^{n+1}+G_{i j} u_{i, j-1}^{n+1}\right\}= \\
= & -A_{i j} u_{i+1, j}^{n}-B_{i j} u_{i+1, j+1}^{n}-D_{i j}{ }_{u_{i-1, j+1}}^{n}-E_{i j} u_{i-1, j}^{n}- \\
- & F_{i j} u_{i-1, j-1}^{n}-H_{i j} u_{i+1, j-1}^{n}+F_{i j} .
\end{aligned}
$$

Equations (B13) and (B14) indicate how the interim solution is updated along each row ( $i=$ constant) or each column $(j=$ constant $)$, respectively, of the numerical domain. Solving for all the values of $u_{i j}{ }^{m+1}$ along one row or one column at a time while using the known values of $u_{i j}{ }^{m}$ to represent the solution on neighboring rows or columns requires the computationally efficient tri-diagonal matrix inversion.

The model solves either Equation (B13) or Equation (B14) on alternate iterations to generate the sequence $u_{i j} m$ The upper triangularization of the tri-diagonal matrix systems represented by Equations (B13) and (B14) are accomplished on the first two iterations, and subsequen iterations require only the calculation of the numerical values of the respective right-hand sides and back substitution. This procedure is especially speedy on vectorprocessing computers such as the CDC Cyber-205 that we used (we gratefully acknowledge the computer support provided by the Geophysical Fluid Dynamics Laboratory of Princeton University). We found that, with a satisfactory initial guess of $u_{i j}{ }^{1}$, convergence to within $0.05 \mathrm{~m} /$ year of the exact solution (of the order of $500 \mathrm{~m} / \mathrm{year}$ ) took approximately 100 iterations. Compared with direct-solution methods we used in earlier studies (MacAyeal and Thomas, 1982 ), the iterative relaxation method described above is approximately three times faster.

\section{Numerical treatment of ice-shelf thermodynamics}

Large-scale heat exchange within an ice shelf is governed by horizontal heat advection, vertical heat conduction, and the effects of surface and basal accumulation. We disregard horizontal conduction, strain heating, and the effects of the temperature- and density-dependent conductivity and heat capacity, because the horizontal spatial resolution we use $(10 \mathrm{~km})$ is too coarse for these effects to be modeled. Nevertheless, both horizontal and vertical processes enter into the heat balance, so the numerical simulation must work with a three-dimensional spatial domain. To facilitate a three-dimensional simulation of a domain with variable thickness, we adopted a stretched vertical coordinate system and subdivided the numerical domain into ten vertical layers as depicted in Figure 17.

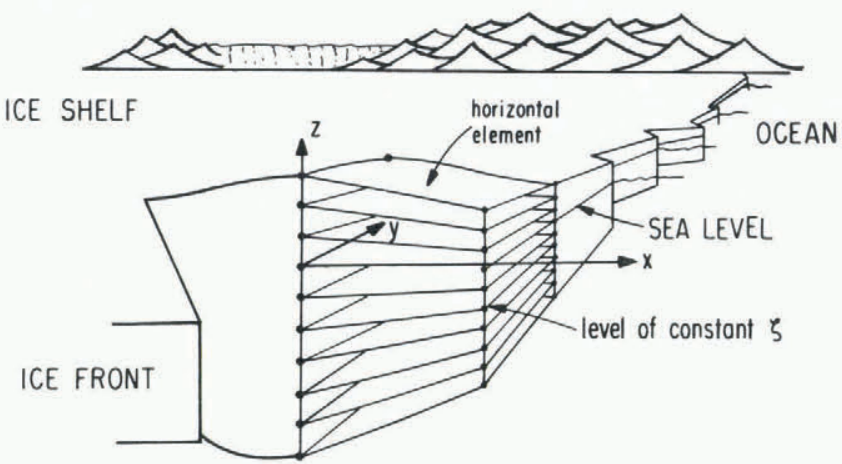

Fig. 17. This diagram displays schematically the treatment of variable ice thickness in the three-dimensional heat-transfer simulation.

The stretched vertical coordinate is defined by

$$
\zeta=\frac{z_{S}-z}{H}
$$

with this definition, $\zeta=0$ at the ice-shelf surface and $\zeta=1$ at the ice-shelf base.

The derivatives of $\theta$ appearing in Equation (2) are transformed as follows:

$$
\begin{gathered}
\left.\frac{\partial \theta}{\partial t}\right|_{z}=\left.\frac{\partial \theta}{\partial t}\right|_{\zeta}-\frac{\zeta}{H} \frac{\partial H}{\partial t} \frac{\partial \theta}{\partial \zeta}+\frac{1}{H} \frac{\partial z}{\partial t} \frac{\partial \theta}{\partial \zeta}, \\
\left.\frac{\partial \theta}{\partial x}\right|_{z}=\left.\frac{\partial \theta}{\partial x}\right|_{\zeta}-\frac{\zeta}{H} \frac{\partial H}{\partial x} \frac{\partial \theta}{\partial \zeta}+\frac{1}{H} \frac{\partial z_{S}}{\partial x} \frac{\partial \theta}{\partial \zeta}, \\
\left.\frac{\partial \theta}{\partial y}\right|_{z}=\left.\frac{\partial \theta}{\partial y}\right|_{\zeta}-\frac{\zeta}{H} \frac{\partial H}{\partial y} \frac{\partial \theta}{\partial \zeta}+\frac{1}{H} \frac{\partial z_{S}}{\partial y} \frac{\partial \theta}{\partial \zeta}, \\
\frac{\partial \theta}{\partial z}=-\frac{1}{H} \frac{\partial \theta}{\partial \zeta}, \\
\frac{\partial^{2} \theta}{\partial z^{2}}=\frac{1}{H} \overline{\frac{\partial}{2}} \frac{\partial^{2} \theta}{\partial \zeta^{2}} .
\end{gathered}
$$


The warp of level surfaces due to horizontal nonuniformities in the depth-averaged density are disregarded in this study.

Vertical velocity with respect to sea-level results from vertical strain and the effects of snow accumulation and basal ablation, and may be derived from the incompressibility condition:

$$
w(z)=\dot{\epsilon}_{z z} z-\dot{A} \frac{\langle\rho\rangle_{z}}{\rho_{\mathrm{w}} H}+\dot{B}\left(1-\frac{\left\langle\rho_{\mathrm{z}}\right.}{H \rho_{\mathrm{w}}}\right) .
$$

Here, $\dot{A}$ and $\dot{B}$ are expressed in units of $\mathrm{m} \mathrm{s}^{-1}$ of pure ice equivalent. The vertical velocity associated with the densification process is disregarded in Equation (B21) because our vertical resolution is insufficient to model this process.

Once transformed to the stretched vertical coordinate system, Equation (2) becomes:

$$
\frac{\partial \theta}{\partial t}=-\nabla_{\zeta} \cdot(u \theta)+\theta(\nabla \cdot u)+\frac{\kappa}{H^{2}} \frac{\partial^{2} \theta}{\partial \xi^{2}}
$$

$$
-[\dot{A}-(\dot{A}+\dot{B}) \zeta] \frac{1}{H} \frac{\partial \theta}{\partial \zeta}
$$

where $\nabla_{\zeta}=\left(\left.\frac{\partial}{\partial x}\right|_{\zeta},\left.\frac{\partial}{\partial y}\right|_{\zeta}\right)$.

Boundary conditions associated with this equation are:

$$
\theta(0)=\theta_{s}(x, y)
$$

and

$$
\begin{aligned}
\theta(1)=\theta_{\mathrm{f}} & =-0.036-0.0499 S-0.00112 S^{2}-7.59 \times \\
& \times 10^{-8} \int_{z b}^{z S} \rho(z) g \mathrm{~d} z \quad\left({ }^{\circ} \mathrm{K}\right)
\end{aligned}
$$

where $\theta_{s}$ is the surface temperature based on observed temperatures in $10 \mathrm{~m}$ bore holes and adjusted to reduce the errors associated with disregard of the density-depth variation (MacAyeal, unpublished [b]), and $\theta(1)$ is the freezing temperature that is a function of salinity $S$ (expressed in parts per thousand) and the hydrostatic pressure (expressed in $\mathrm{N} \mathrm{m}^{-2}$ ) (Fujino and others, 1974). We assumed that $S=34.75^{\circ} / 00$ in accordance with the observed salinities in the open Ross Sea (Jacobs and others, 1979).

An explicit time-stepping procedure coupled with a finite-element Lagrangian treatment of horizontal advection is used to discretize Equation (B22). A finite-difference scheme is used to treat the vertical advection and conduction terms because a finite-element treatment using quadrilateral brick elements was computationally impractical. Using $i, j$, and $k$ as global node identifier indices, with $k=1, \ldots 10$ representing the ten vertical levels, $\ell=1, \ldots 4$ as a local intra-element node identifier, and $n$ and $n+1$ as time-step identifiers, the discrete forms of Equations (B22) through (B24) are written

$$
\begin{aligned}
& \theta_{i j k}^{n+1}=\left.\sum_{\ell=1}^{4} \psi_{\ell} \theta_{\ell k}^{n}\right|_{\tilde{x}, \tilde{y}}+\left.\left.\Delta t \frac{k}{\Delta \zeta_{l=1}^{2}} \sum_{l=1}^{4} \sum_{m=1}^{4} \psi_{\ell}\right|_{\tilde{x}, \tilde{y}} \Psi_{m}\right|_{\tilde{x}, \tilde{y}} \\
& \frac{1}{\left(H_{m}^{n}\right)^{2}}\left(\theta_{\ell, k+1}^{n}+\theta_{\ell, k-1}^{n}-2 \theta_{\ell, k}^{n}\right)-\Delta t \frac{1}{2 \Delta \zeta} .
\end{aligned}
$$

$$
\begin{gathered}
\left.\left.\cdot \sum_{m=1}^{4} \sum_{\ell=1}^{4} \psi_{m}\right|_{\tilde{x}, \tilde{y}} \Psi_{\ell}\right|_{\tilde{x}, \tilde{y}} \frac{1}{\left(H_{m}^{n}\right)}\left[\dot{A}_{m}^{n}-\left(\dot{A}_{m}^{n}+\right.\right. \\
\left.\left.+\dot{B}_{m}^{n}\right) \Delta \xi(k-1)\right] \cdot\left(\theta_{\ell, k+1}^{n}-\theta_{\ell, k-1}^{n}\right), \\
\theta_{i, j, 1}=\theta_{s}
\end{gathered}
$$

and

$$
\theta_{i, j, 10}=\theta_{\mathbf{f}}
$$

where $\tilde{x}$ and $\tilde{y}$ refers to the up-stream position defined by:

$$
\tilde{x}=x_{i j}-\Delta t u_{i j}^{n}
$$

and

$$
\tilde{y}=u_{i j}-\Delta t v_{i j}^{n}
$$

where $u_{i j}=\left(u_{i j}, v_{i j}\right)$ and where the basis-function expansions are performed using the up-stream element containing the point $(\tilde{x}, \tilde{y})$.

The use of the Lagrangian approach over more conventional and straightforward finite-element discretizations of the horizontal advection term is mandated by numerical considerations (Haltiner and Williams, 1980). This approach is equivalent to up-stream differencing in finite-difference models and has similar smoothing characteristics. These smoothing characteristics may be viewed as both an advantage and a disadvantage. All common finite-element and finite-difference schemes exhibit computational dispersion when advecting features that vary over the scale of the grid-lattice spacing. Typically, a single initial "spike' will break into many spikes as a result of the numerics, and some of the initial spike's signal will advect up-stream. The Lagrangian method eliminates artificial up-stream propagation and preferentially damps out lattice-point to lattice-point noise with an effective "diffusivity" varying as $\Delta x / 2$, where $\Delta x$ is the lattice separation. The disadvantage of this smoothing effect is that natural temperature features organized on the limiting scale of model resolution $(10 \mathrm{~km})$ are lost after several time steps. Correct simulation of these small-scale features would require higher spatial resolution than we could achieve. 